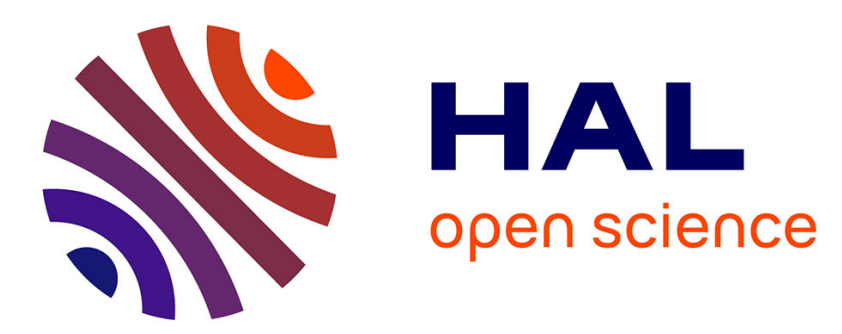

\title{
Accuracy and variability of GPS tropospheric delay measurements of water vapor in the western Mediterranean
}

\author{
J. Haase, M. Ge, E. Calais
}

\section{To cite this version:}

J. Haase, M. Ge, E. Calais. Accuracy and variability of GPS tropospheric delay measurements of water vapor in the western Mediterranean. Journal of Applied Meteorology, 2003, 42 (11), pp.1547-1568. 10.1175/1520-0450(2003)0422.0.CO;2 . hal-00407006

\section{HAL Id: hal-00407006 https://hal.science/hal-00407006}

Submitted on 28 Jan 2021

HAL is a multi-disciplinary open access archive for the deposit and dissemination of scientific research documents, whether they are published or not. The documents may come from teaching and research institutions in France or abroad, or from public or private research centers.
L'archive ouverte pluridisciplinaire $\mathbf{H A L}$, est destinée au dépôt et à la diffusion de documents scientifiques de niveau recherche, publiés ou non, émanant des établissements d'enseignement et de recherche français ou étrangers, des laboratoires publics ou privés. 


\title{
Accuracy and Variability of GPS Tropospheric Delay Measurements of Water Vapor in the Western Mediterranean
}

\author{
JENNIFER HAASE* \\ ACRI-ST, Sophia Antipolis, France \\ MAORONG $\mathrm{GE}^{+}$ \\ CNRS Géosciences Azur, Sophia Antipolis, France \\ HENRIK VEDEL \\ Danish Meteorological Institute, Copenhagen, Denmark \\ ERIC CALAIS* \\ CNRS Géosciences Azur, Sophia Antipolis, France
}

(Manuscript received 12 December 2002, in final form 15 June 2003)

\section{ABSTRACT}

\begin{abstract}
As a preliminary step for assessing the impact of global positioning system (GPS) refractive delay data in numerical weather prediction (NWP) models, the GPS zenith tropospheric delays (ZTDs) are analyzed from 51 permanent GPS sites in the western Mediterranean. The objectives are to estimate the error statistics necessary for future assimilation of GPS ZTD data in numerical models and to investigate the variability of the data in this area. The time series, which were derived continuously from November 1998 to June 2001, are compared with independent equivalent values derived from radiosonde profiles and the High-Resolution Limited-Area Model (HIRLAM) NWP model. Based on over two years of data, the difference between radiosonde and GPS ZTD has a standard deviation of $12 \mathrm{~mm}$ of delay and a bias of $7 \mathrm{~mm}$ of delay. Some sites have biases as high as $14 \mathrm{~mm}$ of delay. The bimodal distribution of residuals, with a higher bias for daytime launches, indicates these biases may be due to radiosonde day-night measurement biases. The biases between the GPS ZTD and HIRLAM estimates are smaller, but the 18-mm ZTD standard deviation is significantly greater. The standard deviation of the residuals depends strongly on the amount of humidity, which produces an annual signal because of the much higher variability of water vapor in the summer months. The better agreement with radiosonde data than HIRLAM estimates indicates that the NWP models will benefit from the additional information provided by GPS. The long-term differences between the observational data sources require further study before GPSderived data become useful for climate studies.
\end{abstract}

\section{Introduction}

Humidity is a highly variable parameter in atmospheric processes and plays a crucial role in atmospheric motions on a wide range of scales in space and time. Limitations in humidity observation accuracy, as well as temporal and spatial coverage, often lead to problems in numerical weather prediction-in particular, predic-

\footnotetext{
* Current affiliation: Department of Earth and Atmospheric Sciences, Purdue University, West Lafayette, Indiana.

+ Current affiliation: GeoForschungsZentrum, Potsdam, Germany.

Corresponding author address: Dr. Jennifer Haase, Dept. of Earth and Atmospheric Sciences, Purdue University, CIVL 1397, West Lafayette, IN 47906.

E-mail: jhaase@purdue.edu
}

tion of clouds and precipitation. The verification of humidity simulations in operational weather forecasts and climate modeling is also difficult because of the lack of high temporal and spatial resolution data. Ground-based global positioning system (GPS) receivers have been proposed as a possible data source (Bevis et al. 1992) to improve both model validation and the initial model state used in forecasts.

The refractive delay of GPS radio signals measured by ground-based receivers is a function of pressure, temperature, and water vapor pressure. The hydrostatic component of the zenith delay can be estimated from surface pressure measurements and removed, leaving the nonhydrostatic component of the refractive delay, which is nearly proportional to the content of water vapor and, hence, is called the wet delay. 
The refractive delay of radio waves in the atmosphere is a large source of error for precise positioning using space geodetic measurement techniques, contributing a range error in the zenith direction on the order of 2.4 $\mathrm{m}$. This motivated the early work on methods to model the error source (Saastamoinen 1972; Davis et al. 1985; Askne and Nordius 1987; Elgered et al. 1991) in order to remove it and, thus, increase the accuracy of space geodetic positioning estimates. Herring (1990) and Tralli and Lichten (1990) developed methods to include the zenith delays as unknown parameters to be simultaneously estimated in the positioning calculation. Bevis et al. (1992) proposed the use of these estimated delays as a means for studying the atmosphere.

Ground-based GPS receivers are an attractive source of humidity data for weather prediction in that they are portable, are economic, and provide measurements that are not affected by rain and clouds. They cannot independently provide a humidity profile as do radiosondes (RS), but they have the advantage of providing automated continuous data whereas operational radiosondes usually provide two or four measurements per day. Other ground-based measurements, such as water vapor radiometers or photometers, are affected by rain and clouds.

Many authors carried out studies to increase the accuracy of the technique, typically using a small number of stations. Rocken et al. (1993) were the first to demonstrate agreement between water vapor radiometer(WVR) and GPS-derived relative estimates of integrated water vapor (IWV), with a level of agreement of about $1 \mathrm{~kg} \mathrm{~m}^{-2}$. Evaluation of absolute rather than relative IWV was made possible by extending the horizontal extent of the network, which also reduced biases in the estimates (Duan et al. 1996; Tregoning et al. 1998). Systematic errors were reduced by using improved mapping functions relating the delay observed at a given satellite elevation to the zenith delay, and by using improved antenna phase-center correction models (Niell 2000; Fang et al. 1998; Mader 1999). Tests that included gradients as a first approximation for laterally varying refractivity structure around the sites demonstrated that the estimation of zenith delays is robust with or without including these gradients (Ruffini et al. 1999; Bar-Sever et al. 1998). One long-term study (Emardson et al. 2000) detected instrumental biases due to antenna radomes and the resulting contamination of network solutions. This study used independent data from other instruments, in particular water vapor radiometers, to demonstrate the accuracy of the data. It has been demonstrated that the integrated water vapor can be retrieved using groundbased GPS observations with the same level of accuracy as radiosondes and microwave radiometers (Elgered et al. 1997; Bevis et al. 1992; Rocken et al. 1995; Duan et al. 1996; Emardson et al. 1998; Tregoning et al. 1998).

As the technique has improved, the potential of this method has been realized as an important source of humidity observations for numerical weather prediction
(NWP) models (Kuo et al. 1996; Zou and Kuo 1996) and for climate studies (Yuan et al. 1993). There have been efforts in North America and Europe dedicated to exploiting the data to improve forecasting. The first study of its kind was the "GPS/STORM" experiment, which took place in the high-tornado-risk area of the midwestern United States (Rocken et al. 1995). This experiment compared GPS water vapor measurements with radiosonde measurements during a time period that included more than six major storms and demonstrated the validity of the method. Since then, the U.S. National Oceanic and Atmospheric Administration (NOAA) has installed an operational network to further research the use of a ground-based GPS-integrated water vapor observing system for weather forecasting (Smith et al. 2000; Gutman and Benjamin 2001). GPS IWV data from an extensive network of stations in the Baltic region were compared with NWP model delayed-mode assimilation reanalyses and forecasts for a 4-month period (Yang et al. 1999). The difference between the NWP reanalyses and GPS IWV for 25 sites had a bias of $-0.1 \mathrm{~kg} \mathrm{~m}^{-2}$ and a root-mean-square (rms) error of $2.3 \mathrm{~kg} \mathrm{~m}^{-2}$. For some sites the bias was as high as $2.4 \mathrm{~kg} \mathrm{~m}^{-2}$ and the rms was as high as $3.4 \mathrm{~kg} \mathrm{~m}^{-2}$, though the data that were used were later found to contain errors due to the sitespecific radome equipment and have since been improved (Emardson et al. 2000). In general, the level of agreement between the GPS and the NWP reanalyses was approximately the same as the agreement of the reanalyses with the radiosondes. An extensive array of GPS receivers installed in Japan for earthquake research is now being used by the Japan Meteorological Agency (JMA) to retrieve IWV for planned assimilation in NWP models. In preliminary comparisons with the JMA objective analyses, the IWV was shown to track incoming storm fronts, but the data had some biases on the order of $2-4 \mathrm{~kg} \mathrm{~m}^{-2}$ (Iwabuchi et al. 2000).

Concurrent with efforts in the United States to incorporate the GPS zenith tropospheric delay (ZTD) data into NWP models, the Meteorological Applications of GPS-Integrated Column Water Vapor in the Western Mediterranean (MAGIC) project was begun in Europe with similar objectives (Haase et al. 2001). MAGIC was a 3-yr project financed in part by the European Commission. The project objectives were to test the usefulness of the GPS data for NWP model validation, to develop the assimilation algorithms necessary for incorporating this data into NWP models, and to study the long-term use of these data in climate model validation.

The focus of this paper is the presentation of error statistics from the comparison of the GPS ZTD with radiosonde data and the HIRLAM 6-h forecasts. This will provide the necessary input for determining the error covariance matrix of the observation operator in the three-dimensional and four-dimensional variational assimilation algorithms in the HIRLAM forecasts. The comparison among the three datasets has been carried out continuously over a time period greater than two 
annual cycles. The present study provides a comparison in a region that is climatically very different from the Baltic (Yang et al. 1999) and the midwestern United States (Smith et al. 2000), and, thus, provides additional important insight for effective use of the data.

\section{GPS data processing}

a. Network design, station distribution, and data flow

The data processing carried out for the MAGIC project includes data from 51 permanent GPS stations (Fig. 1). In order to reduce the computational load of the network geodetic solution, we divided the GPS network into three subnetworks - one in France, one in Italy, and one in Spain-with each subnetwork containing six common International GPS Service (IGS) reference stations. The three estimates of tropospheric delay at the common IGS stations are used to monitor the consistency of each subnetwork solution and are used for testing the sensitivity of the ZTD solutions to the network geometry.

The GPS data are collected daily in the receiver-independent exchange (RINEX) format with a 30-s sampling rate from the IGS data centers and other agencies responsible for permanent regional station archives. Surface meteorological data taken at the GPS sites (pressure, temperature, relative humidity) are also downloaded where they are available. The RINEX data are quality checked and stored until the final precise IGS orbits (Kouba and Mireault 1998) become available, approximately 2 weeks later.

The GPS data are processed at three institutions involved in the MAGIC project to ensure consistent results independent of the software used. The Centre National de la Recherche Scientifique (CNRS) Géosciences Azur laboratory in France processes all MAGIC stations, using the GPS at Massachusetts Institute of Technology (GAMIT) software (Bock et al. 1986; King and Bock 1999). The Institute for Space Studies of Catalonia (IEEC) in Spain processes a subset of IGS stations using the GPS Inferred Positioning System (GIPSY) software point-positioning strategy (Webb and Zumberge 1997; Zumberge et al. 1997; Ruffini et al. 1999; Flores et al. 2000). The Italian Space Agency (ASI) in Italy processes the Italian stations using the GIPSY software and has tested both a network-processing and a point-positioning strategy (Pacione et al. 2001). The ZTDs estimated by the three centers are then archived so that an ongoing, routine comparison among subnetworks, processing centers, and radiosonde and HIRLAM data can be used to validate the results. The entire procedure has been automated and runs routinely with very limited user input. Here, we present the results from the CNRS Géosciences Azur data-processing center.

\section{b. Zenith tropospheric delay retrieval}

The quantity observed by the GPS receiver is the interferometric phase measurement of the distance from the GPS satellites to the receiver. The processing software must resolve or model the orbital parameters of the satellites, solve for the transmitter and receiver positions, account for ionospheric delays, and solve for phase cycle ambiguities and clock drifts, in addition to solving for the tropospheric delay parameters of interest. This requires the same type of GPS data-processing software as that which is used for high-precision geodetic measurements. We use the GAMIT software (Bock et al. 1986; King and Bock 1999), which solves for the ZTD and other parameters using a constrained batch least squares inversion procedure.

The tropospheric delay for a zenith path is the integral of the refractivity $N$ over height in the atmosphere. The refractivity can be described as a function of temperature $T$, the partial pressure of dry air $P_{d}$, and the partial pressure of water vapor $e$ (Smith and Weintraub 1953; Thayer 1974; Davis et al. 1985):

$$
N=k_{1} \frac{P_{d}}{T Z_{d}}+k_{2} \frac{e}{T Z_{w}}+k_{3} \frac{e}{T^{2} Z_{w}},
$$

where $k_{1}, k_{2}$, and $k_{3}$ are constants that have been determined experimentally, and $Z_{d}$ and $Z_{w}$ are the compressibilities of dry air and water vapor, respectively. The best statistical estimates of the constants based on published results (Bevis et al. 1994) are $k_{1}=0.7760 \mathrm{~K}$ $\mathrm{Pa}^{-1}, k_{2}=0.704 \mathrm{~K} \mathrm{~Pa}^{-1}$, and $k_{3}=0.03739 \times 10^{5} \mathrm{~K}^{2}$ $\mathrm{Pa}^{-1}$.

The ZTD is, therefore,

$$
\begin{aligned}
\mathrm{ZTD} & =10^{-6} \int_{z_{\mathrm{ant}}}^{\mathrm{toa}} N d z \\
& =10^{-6} \int_{z_{\mathrm{ant}}}^{\mathrm{toa}} k_{1} \frac{P_{d}}{T Z_{d}}+k_{2} \frac{e}{T Z_{w}}+k_{3} \frac{e}{T^{2} Z_{w}} d z,
\end{aligned}
$$

where $z_{\text {ant }}$ is the height of the GPS antenna and toa is the top of the atmosphere.

Using an equation of state of the form $P_{i}=\rho_{i} R_{i} Z_{i} T$, for the $i$ th component of a mixture of gases, this can be rewritten as

$$
\begin{aligned}
\mathrm{ZTD}= & 10^{-6} k_{1} R_{d} \int_{z_{\mathrm{ant}}}^{\mathrm{toa}} \rho d z \\
& +10^{-6} R_{v}\left(k_{2}-\varepsilon k_{1}\right) \int_{z_{\mathrm{ant}}}^{\mathrm{toa}} \rho_{v} d z \\
& +10^{-6} R_{v} k_{3} \int_{z_{\text {ant }}}^{\text {toa }} \frac{\rho_{v}}{T} d z
\end{aligned}
$$

where $\rho$ is density, $\rho_{v}$ is the contribution of water vapor to the density of the air, $R_{d}$ is the gas constant for dry air, $R_{v}$ is the gas constant for water vapor, and $\varepsilon=R_{d} / R_{v}$ is the ratio of the gas constants for dry air and water vapor.

The ZTD may now be considered as the sum of two terms, 


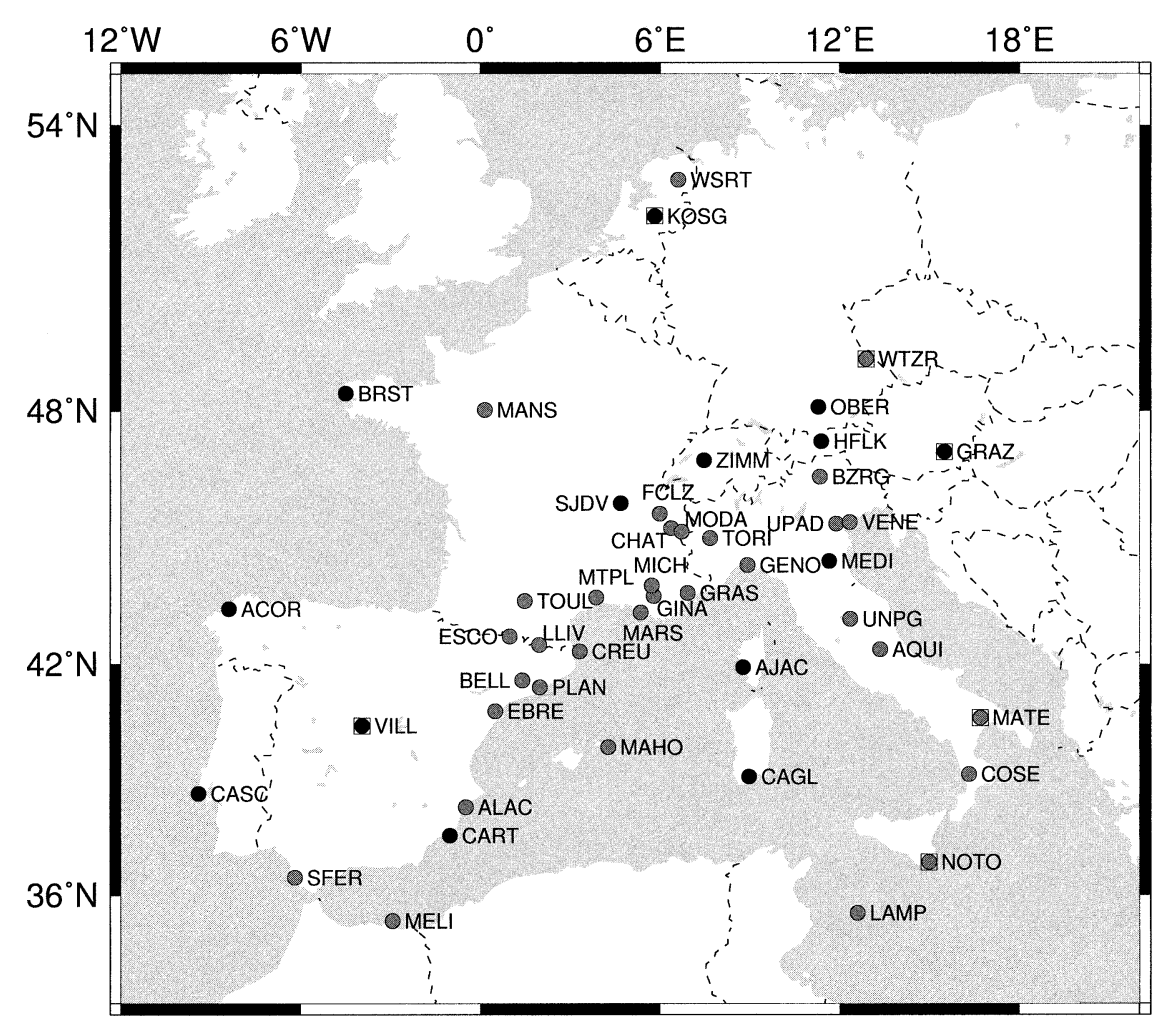

FIG. 1. MAGIC GPS station distribution. Shaded circles indicate sites with radiosonde sites within $50 \mathrm{~km}$. Boxes indicate the six sites used as common reference sites in the processing.

$$
\mathrm{ZTD}=\mathrm{ZHD}+\mathrm{ZWD}
$$

where the hydrostatic delay is

$$
\mathrm{ZHD}=10^{-6} k_{1} R_{d} \int_{z_{\mathrm{ant}}}^{\text {toa }} \rho d z,
$$

and the nonhydrostatic or "wet" delay is

$$
\begin{aligned}
\mathrm{ZWD}= & 10^{-6} R_{v}\left(k_{2}-\varepsilon k_{1}\right) \int_{\text {zant }}^{\text {toa }} \rho_{v} d z \\
& +10^{-6} k_{3} R_{v} \int_{z_{\text {ant }}}^{\text {toa }} \frac{\rho_{v}}{T} d z .
\end{aligned}
$$

The zenith hydrostatic delay (ZHD) typically ranges from 2.0 to $2.3 \mathrm{~m}$ at sea level, and the zenith wet delay (ZWD) varies from approximately $0.05-0.06 \mathrm{~m}$ at the Poles to $0.30-0.35 \mathrm{~m}$ in the Tropics.

The GPS measurement is made along the line of sight from the ground station to the satellite, which is rarely in the zenith direction. Therefore, mapping functions are needed to take into account the dependence on satellite elevation. We use the Neill mapping functions, which are different for the hydrostatic and wet component of the delay. These have been shown to be less sensitive to the lower limit of elevation angles when compared with other mapping functions (Niell 2000). The mapping is solely a function of elevation and not azimuth. This is valid when the data used are limited to measurements collected more than $10^{\circ}$ above the horizon and when the time of the measurement is long enough to average out the smaller-scale variations that provide the largest azimuthally dependent signals. It has been shown that the values obtained for zenith delays are insensitive to whether lateral gradient parameters are included in the solution (Bar-Sever et al. 1998). The total tropospheric delay is then modeled as

$$
\mathrm{ZTD}(\Theta)=\mathrm{ZHD} \times M^{h}(\Theta)+\mathrm{ZWD} \times M^{w}(\Theta),
$$

where $M(\Theta)$ is the mapping function that accounts for the elevation angle and first-order refractive bending of the pathlength through the troposphere, the superscripts $h$ and $w$ refer to hydrostatic and wet, respectively, and $\Theta$ is the satellite elevation angle.

The GAMIT software parameterizes ZTD as a stochastic variation from the Saastamoinen model (Saastamoinen 1972), with piecewise linear interpolation inbetween solution epochs. GAMIT is very flexible in that it allows a priori constraints of varying degrees of uncertainty. The variation from the hydrostatic delay is constrained to be a Gauss-Markov process with a specified power density of $2 \mathrm{~cm} \mathrm{~h}^{-1 / 2}$, referred to below as the "zenith tropospheric parameter constraint."

We designed a 12-h sliding window strategy in order to process the shortest data segment possible without degrading the accuracy of ZTD estimates. The Gauss- 
TABLE 1. Table of parameters used in the MAGIC data processing.

IGS final orbits are used; orbits are reestimated across day boundaries.

Reference frame is the ITRF97.

Network station constraints are provided on six IGS sites.

Data are processed in three subnetworks.

Zenith parameters constraint is a Gauss-Markov process with power density $2 \mathrm{~cm}(\mathrm{~h})^{-1 / 2}$

Cutoff satellite elevation angle is $10^{\circ}$.

12-h sliding window is used, with ZTD extracted from the central $4 \mathrm{~h}$

GPS data sampling interval is $60 \mathrm{~s}$.

Antenna phase-pattern corrections are applied following the IGS recommendations (Mader 1999).

Zenith delay is estimated at 15 -min intervals.

Tropospheric delay is mapped into zenith delay using the Niell mapping functions (Niell 2000).

GPS observables are doubly differenced LC (ionosphere free) observations, ambiguity free solution.

Bad satellite and station observations are removed automatically, based on the corresponding phase observation residuals.

Markov process provides an implicit constraint on the ZTD estimate at a given epoch from observations at preceding and following epochs, which means that the accuracy is expected to be lower at the beginning and end of each window. We, therefore, extract ZTD estimates from the middle $4 \mathrm{~h}$ of the 12 -h window and then move the window forward by $4 \mathrm{~h}$.

Station coordinates are constrained to values from a precise long-term geodetic solution in order to avoid any correlation between coordinates and ZTD estimates. Any errors in the coordinates, in particular the height component, would otherwise directly bias the estimated ZTD. Tregoning et al. (1998), for instance, showed that a 5$\mathrm{cm}$ height error at a fixed station could map into a 0.5 $\mathrm{mm}$ ZTD bias at another site $800 \mathrm{~km}$ away. Precise estimates of both station coordinates and velocities in the same reference frame as the IGS satellite orbits are needed to take into account the station position change caused by global and regional tectonic movements. We, therefore, compute a geodetic solution from the data accumulated on a weekly basis in order to account for the GPS site motions and to ensure the best possible a priori site position. We tightly constrain the positions of six stations of the IGS network (GRAZ, KOSG, NOTO, VILL, WTZR, ZIMM) to the latest 1997 International Terrestrial Reference Frame (ITRF97) values and the satellite orbits to the final IGS ephemerides. We fit new parameters to the IGS ephemerides in order to have smooth orbit estimates across the day boundary. These processing parameters are summarized in Table 1.

To refine our data-processing strategy, we performed a systematic test of all the parameters that could have a significant impact on the ZTD estimates during the GPS analysis: the cutoff satellite elevation angle, the tropospheric constraint, the variation of orbit quality [using Scripps Institution of Oceanography (SIO), Jet Propulsion Laboratory (JPL), and IGS precise final orbit products], the reference network, and uncertainties in station coordinates. The test network included the MAGIC reference network (six IGS stations) and eight other stations, most of them having radiosonde observations within $50 \mathrm{~km}$. We performed the test on a dataset that covers the period from 10 May to 10 June 1999. The maximum differences are on the order of $0.1 \pm 1.5$ mm of delay. In addition, we compared the solutions of the three processing centers (ASI, CNRS, and IEEC), using different software packages and strategies, and found differences of $1 \pm 7 \mathrm{~mm}$ delay. This standard deviation of $7 \mathrm{~mm}$ is the best estimate of the random error of the GPS ZTD measurements.

For the main objectives of the MAGIC project, the GPS-derived ZTD, rather than integrated water vapor, will be used directly as an assimilated variable in the $3 \mathrm{D}$ variational system. However, at eight stations of the network, surface pressure measurements are available for part of the 2.5-yr period. For these sites, the hydrostatic delay is calculated and the ZTDs are transformed routinely into IWV for validation purposes in the following manner. Saastamoinen 1972 (see, also, Davis et al. 1985) derived an expression for the ZHD given in Eq. (5) using the hydrostatic assumption and adopting a standard atmospheric temperature profile. This yields a function for the gravitational acceleration at the center of mass of the atmospheric column, which is a function solely of latitude $\theta$ and height above the geoid $H$ :

$$
\begin{aligned}
\mathrm{ZHD}= & {\left[(0.0022768 \pm 0.0000005) \mathrm{m} \mathrm{hPa}^{-1}\right] } \\
& \times \frac{P_{0}}{f(\theta, H)},
\end{aligned}
$$

where $P_{0}=$ surface pressure $(\mathrm{hPa})$,

$$
\begin{aligned}
g_{m} & =0.784 \mathrm{~m} \mathrm{~s}^{-2}[f(\theta, H) \pm 0.0001], \text { and } \\
f(\theta, H) & =1-0.00266 \cos 2 \theta-0.00028 \mathrm{~km}^{-1} \times H .
\end{aligned}
$$

In order to derive an expression for wet delay, following Askne and Nordius (1987), we define the mean temperature of water vapor in the atmospheric column as

$$
T_{m}=\frac{\int_{z_{\text {ant }}}^{\text {toa }} \rho_{v} d z}{\int_{z_{\text {ant }}}^{\text {toa }} \frac{\rho_{v} d z}{T}} .
$$

The definition of IWV $\left(\mathrm{kg} \mathrm{m}^{-2}\right)$ of a column above height $z_{\text {ant }}$ is defined as

$$
\mathrm{IWV}=\int_{z_{\mathrm{ant}}}^{\mathrm{toa}} \rho_{v} d z .
$$

Using these expressions, the wet component of the delay ZWD can be written as 


$$
\mathrm{ZWD}=10^{-6} \frac{R_{d}}{\varepsilon}\left(-k_{1} \varepsilon+k_{2}\right) \mathrm{IWV}+10^{-6} \frac{R_{d} k_{3}}{\varepsilon} \frac{\mathrm{IWV}}{T_{m}},
$$

and this can be inverted to solve for IWV:

$$
\mathrm{IWV}=\frac{10^{6}}{R_{v}\left(-k_{1} \varepsilon+k_{2}+\frac{k_{3}}{T_{m}}\right)} \text { ZWD. }
$$

Bevis et al. (1992) derived a linear relationship between $T_{m}$ and the surface temperature $T_{s}$, based on radiosonde profiles from 9000 sites in the United States,

$$
T_{m}=70.2+0.72 T_{s},
$$

in order to estimate IWV without access to information about the whole atmospheric column to provide $T_{m}$. Emardson and Derks (2000) improved the derivation of $T_{m}$ by fitting 120000 radiosonde profiles from 30 sites in Europe with a quadratic regression. This is the formula that we use to transform ZWD to IWV:

$$
\mathrm{ZWD}=\left(a_{0}+a_{1} \Delta T+a_{2} \Delta T^{2}\right) \mathrm{IWV},
$$

where $\Delta T=T_{s}-T_{\mathrm{av}} ; T_{s}$ is the surface temperature; and where $T_{\text {av }}, a_{0}, a_{1}$, and $a_{2}$ are the following constants:

$$
\begin{aligned}
T_{\mathrm{av}} & =283.49 \mathrm{~K}, \\
a_{0} & =6.458 \mathrm{~m}^{3} \mathrm{~kg}^{-1}, \\
a_{1} & =-1.78 \times 10^{-2} \mathrm{~m}^{3} \mathrm{~kg}^{-1} \mathrm{~K}^{-1}, \text { and } \\
a_{2} & =-2.2 \times 10^{-5} \mathrm{~m}^{3} \mathrm{~kg}^{-1} \mathrm{~K}^{-2} .
\end{aligned}
$$

Whereas previous studies have concentrated on demonstrating the quality of GPS-derived IWV, we have concentrated on evaluating zenith tropospheric delay as the final product rather than precipitable water or integrated water vapor. This is done, first of all, because the ZTD is a more direct product of the raw GPS observations that is free of errors due to pressure sensors and uncertainties in the derivation of $T_{m}$. Second, ZTD is expected to become the preferred measure in modern NWP models using 3D or 4D variational data assimilation. Such systems combine different types of observations with a recent forecast field in an optimal way, resulting in the statistical best estimate of the current state of the atmosphere. For this to work properly, a precise statistical description is necessary for the errors of each type of observation (and any existing correlations), as well as the errors of the forecast variables. If supplementary observations at the GPS site exist, it is beneficial to assimilate them in parallel with ZTD in the NWP systems rather than to use them to transform ZTD to IWV. However, certain data assimilation systems need IWV rather than ZTD. Similarly IWV will be preferred in certain types of climate studies. Note that $1 \mathrm{~kg} \mathrm{~m}^{-2}$ of IWV or $1 \mathrm{~mm}$ of PW corresponds to approximately $6.4 \mathrm{~mm}$ of zenith tropospheric delay.

\section{Characteristics and time variability of the GPS ZTD data}

The GPS ZTD time series have been analyzed for 2.5 $\mathrm{yr}$ for the majority of the 51 sites of the network. The ZTD time series for a typical station, such as ZIMM (Fig. 2), shows an annual variation with lower values in the winter months and higher values in the summer months. We determined the annual variation for each site as the best-fit sinusoid. The annual variation in ZTD ranges from 25 to $75 \mathrm{~mm}$, depending on the site, with most sites around $40-50 \mathrm{~mm}$. Sites on the Atlantic coast have lower-amplitude annual variation, probably because of the moderating effect of the ocean on climate (Fig. 3). Sites on the lee side of the Alps have higher annual variation, possibly due to the combined effects of a rain shadow in the winter and high moisture from the Mediterranean in the summer. The annual variation is due primarily to the wet component, even though the wet delay is only $5 \%$ of the total delay.

We estimate the higher-frequency variability by taking the rms of the ZTD time series after removing the sinusoidal annual variation. This higher-frequency variability ranges from 22 to $40 \mathrm{~mm}$ of delay, once again primarily due to the wet component. The variability depends on the total water vapor content and, hence, shows a dependence on altitude of the station (Fig. 4). Higher-altitude inland stations tend to have lower variability. Sites with some of the highest variability are found at coastal Mediterranean stations. The northern Mediterranean stations, in particular, are located in a region well known for large abrupt changes in the weather associated with secondary cyclogenesis in the Gulf of Genoa (Doswell et al. 1998).

An often cited advantage of the GPS ZTD data, relative to other sources of data, is the high sampling rate of 1 per $15 \mathrm{~min}$, which comes at no extra operational cost. The spatial resolution of the GPS ZTD data is effectively limited by averaging raw observations over an elevation angle range from $10^{\circ}$ to the vertical. Given a humidity scale height of $2 \mathrm{~km}$ and an average velocity of advection of air masses on the order of $30 \mathrm{~km} \mathrm{~h}^{-1}$, this implies that independent measurements of the humidity structure would be made at about 40 min intervals. The 15-min ZTD interval oversamples the expected time variation, and so we apply a ZTD variance constraint in the processing with a power density of 2 $\mathrm{cm} \mathrm{h}^{-1 / 2}$. Though the same constraint was applied to all sites, we found that the true variance of the ZTD data is different depending on the geographic location.

Structure functions are one way to characterize the temporal variability of the time series, as shown by Jarlemark and Elgered (1998). We calculate structure functions $D$ for the ZTD time series using the definition

$$
D(\tau) \equiv\left\langle[\operatorname{ZTD}(t+\tau)-\operatorname{ZTD}(t)]^{2}\right\rangle,
$$

where $t$ is the time epoch of the measurement, $\tau$ is the time lag, and the angle brackets indicate the expected 


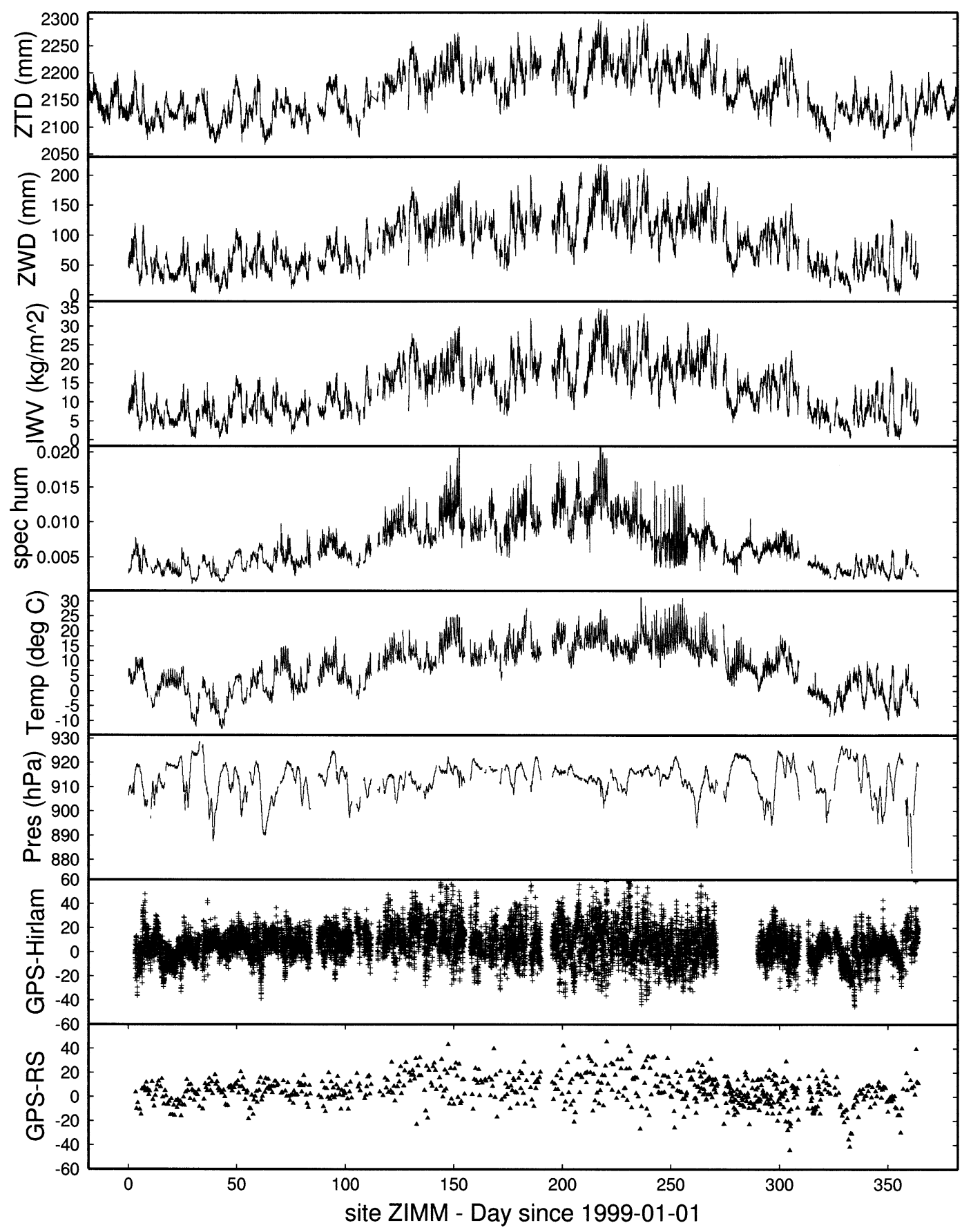

FIG. 2. From top to bottom: zenith tropospheric delay $(\mathrm{mm})$, zenith wet delay $(\mathrm{mm})$, integrated water vapor $\left(\mathrm{kg} \mathrm{m}^{-2}\right)$, surface specific humidity, surface temperature $\left({ }^{\circ} \mathrm{C}\right)$, surface pressure $(\mathrm{hPa})$, difference between GPS ZTD and HIRLAM ZTD ( $\mathrm{mm}$ of delay), and difference between GPS ZTD and radiosonde ZTD ( $\mathrm{mm}$ of delay) measured at site ZIMM from 1 Jan 1999 to 31 Dec 1999.

value or average. The structure function generally follows a power law,

$$
D(\tau)=c \times \tau^{\alpha},
$$

where $c$ is a constant, termed the variance rate, and $\alpha$ is the power-law index, with values ranging between 1
(Jarlemark and Elgered 1998) and 2/3 (Treuhaft and Lanyi 1987). Examples of average structure functions from two high-latitude (ZIMM and WTZR) and two low-latitude (NOTO and LAMP) sites for the entire length of the time series are shown in Fig. 5. The value at the lower-limit time lag indicates the sample-to-sam- 


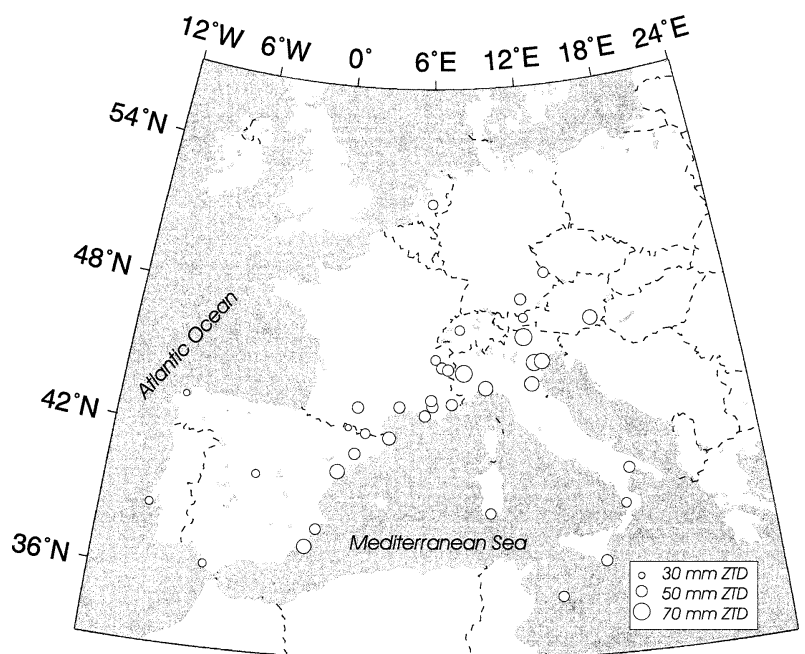

FIG. 3. Geographical dependence of the amplitude of the annual variation of GPS ZTD. A symbol scaled with the size of the annual term is plotted at the location of the GPS site.

ple variance at 30-min intervals. We fit a constant, $c$, to the structure function for each site for time lag from $30 \mathrm{~min}$ to $2.5 \mathrm{~h}$, assuming a value for $\alpha$ of 1 . We find a variance rate that ranges from 500 to $2000 \mathrm{~mm}^{2}$ day $^{-1}$, depending on the site, with sites at lower latitudes, in general, having higher variance rates. We believe this indicates that water vapor fields have higher variability in the low midlatitudes because the distribution is less dominated by synoptic-scale dynamics. The time variability and its latitudinal dependence will be discussed further in the HIRLAM comparison section.

Most, but not all, of this variability is predicted by a simple correlation with temperature and surface humidity because of the combined effects of increasing evaporation and a strong increase in the water vapor saturation pressure. Mendes (1999) reviewed the accuracy of several models for calculating ZWD based solely on surface parameters and a simple functional dependence on height. Based on radiosonde data, he determined that the ZWD could be predicted with a standard deviation of $\pm 27 \mathrm{~mm}$ for sites in the continental United States. We calculate a regression fit to ZWD as a function of specific humidity measured locally at the antenna height, $q_{\text {surf }}$. This gives a correlation coefficient of 0.88 and a residual of $\pm 23.9 \mathrm{~mm}$ :

$$
\mathrm{ZWD}=1.7555 \times 10^{4} q_{\text {surf }}-5.0 \pm 23.9 \mathrm{~mm} \text {. (19) }
$$

The mean wet delay over this time period is 123.0 $\mathrm{mm}$. The standard deviation of $\pm 23.9 \mathrm{~mm}$, which is not correlated with surface humidity measurements, is due to the humidity variations in the upper atmosphere. This upper-atmosphere signal is 4 times the 7-mm precision level of the GPS ZTD data that was estimated from the processing methodology intercomparison. This gives an indication of the significance of the impact GPS data

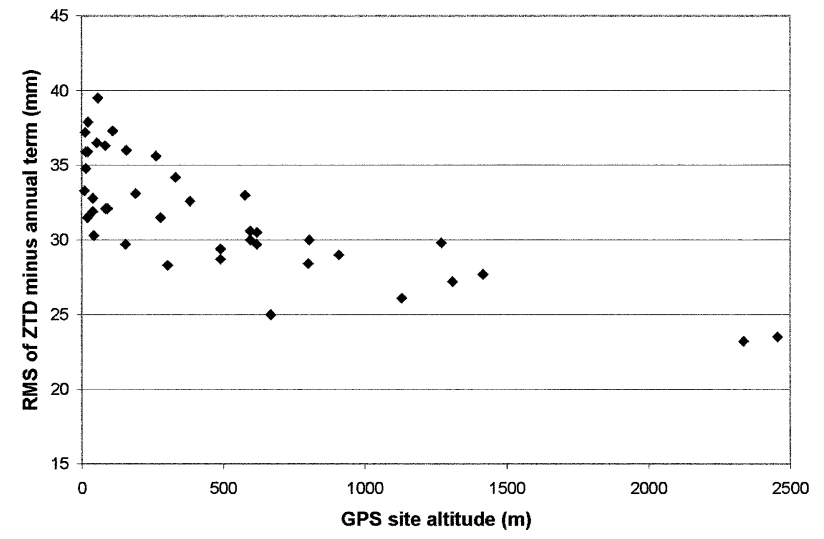

FIG. 4. High-frequency variability, measured here as the rms variation of the ZTD time series after the annual term has been removed, is on the order of $20-40 \mathrm{~mm}$ of ZTD. The variability shows a dependence on the water vapor content through the inverse dependence on altitude of the site.

would have in data assimilation over a simple climatological representation based on surface measurements.

\section{Comparison with radiosonde data}

Radiosondes are the primary operational source of upper-air humidity observations. Therefore, they are a good source of independent validation data for demonstrating the potential value of GPS ZTD data for future assimilation.

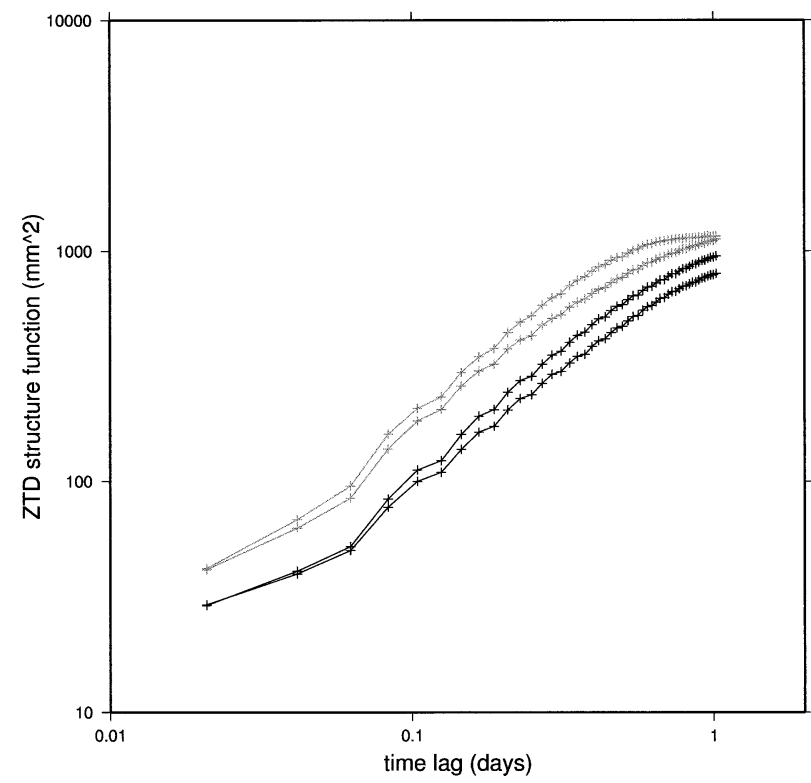

FIG. 5. Structure functions for low-latitude sites NOTO and LAMP (gray) and high-latitude sites ZIMM and WTZR (black). Average structure functions are calculated for time lags from $30 \mathrm{~min}$ to 1 day using 2 yr of data. 


\section{a. Radiosonde data processing}

The radiosonde profiles come from the World Meteorological Organization (WMO) Global Telecommunications Service (GTS) and, for the purpose of this project, are provided by the Danish Meteorological Institute (DMI). As part of the automatic processing procedure, we download radiosonde data regularly from the DMI for launch sites closer than $50 \mathrm{~km}$ to the GPS sites. To generate values from the radiosonde profiles that are directly comparable to the GPS ZTD data, the integral in Eq. (3) is transformed from an integral over geometric height to an integral over pressure, using the assumption of hydrostatic equilibrium, $d P=-g(z) \rho(z) d z$,

$$
\begin{aligned}
\mathrm{ZTD}= & 10^{-6} k_{1} R_{d} \int_{0}^{P_{\text {ant }}} \frac{1}{g} d P \\
& +10^{-6} R_{v} \int_{0}^{P_{\text {ant }}} q \frac{1}{g}\left(-k_{1} \varepsilon+k_{2}+\frac{k_{3}}{T}\right) d P,
\end{aligned}
$$

where $P_{\text {ant }}$ is the pressure at the antenna height, and $q$ $=\rho_{v} / \rho$ is the specific humidity.

The calculation of the ZTD from RS records for comparison with GPS ZTD is done in a number of steps as follow: 1) quality checking of radiosonde profiles; 2) conversion of dewpoint temperatures to relative and specific humidity; 3 ) transformation of the radiosonde profile to correct for altitude offsets between GPS and radiosonde sites; 4) numerical integration of the transformed profile, calculating separately ZHD, ZWD, and IWV, and compensating for the change in $g$ with pressure; and 5) addition of the contribution to delays from above the radiosonde profile.

\section{1) QuALITY CHECKING OF RADIOSONDE PROFILES}

First we reject profiles that start high above ground level, leading to initial pressure levels that are not within $100 \mathrm{hPa}$ of that expected for a standard atmosphere at that latitude and altitude. Then, we reject profiles that have large gaps (greater than $200 \mathrm{hPa}$ ) in pressure between recordings of temperature or humidity, which can occur when unreliable data are discarded, particularly for air temperatures below $-40^{\circ} \mathrm{C}$. A decrease in humidity within the profile at the 100-200-hPa level would otherwise go undetected.

\section{2) CONVERSION FROM DEWPOINT TEMPERATURES TO SPECIFIC HUMIDITY}

We minimize systematic biases that can be introduced when converting between dewpoint and relative or specific humidity using inconsistent methods (J. Elms 2000, personal communication). The bias is on the order of $2.3 \mathrm{~mm}$ of ZTD between certain standard conversion formulas (Vedel 2000, 2001). First, we invert the conversion formula used by Digicora radiosonde stations, the most widely used in Europe, leading to an approx- imation of the relative humidity actually measured by the sensor,

$$
\mathrm{rh} \approx \frac{\mathrm{esat}_{\mathrm{approx}}\left(T_{\mathrm{dew}}\right)}{\mathrm{esat}_{\mathrm{approx}}(T)},
$$

where $T_{\text {dew }}$, and $T$ are taken from the GTS radiosonde report; and the function for the saturation pressure esat $_{\text {approx }}$ is given by

$$
\text { esat }_{\text {approx }}=R_{2} \exp \left[\frac{R_{3}\left(T-T_{0}\right)}{T-R_{4}}\right],
$$

with $R_{2}=611.21 \mathrm{~Pa}, R_{3}=17.502 \mathrm{~K}, R_{4}=32.19 \mathrm{~K}$, and $T_{0}=273.16 \mathrm{~K}$.

This approach gives good estimates of relative humidity in an average sense (Vedel 2000, 2001), because most of the sites are Digicora stations. Second, the calculated estimate of the measured relative humidity is converted to the specific humidity using a more precise formula [taken from the NWP HIRLAM model, e.g., Sass et al. (1999)],

$$
q=\frac{(\varepsilon)(\mathrm{rh})\left(\mathrm{esat}_{\mathrm{HIRLAM}}\right)(T)}{P-(\mathrm{rh})\left(\mathrm{esat}_{\mathrm{HIRLAM}}\right)(T)(1-\varepsilon)},
$$

with $P$ and $T$ provided from the radiosonde report, and rh from Eq. (21). The formula for esat ${ }_{\text {HIRLAM }}$ is given by

$$
\text { esat }_{\text {HIRLAM }}=R_{2} \exp \left[\frac{R_{3}\left(T-T_{0}\right)}{T-R_{4}}\right],
$$

with $R_{2}=610.78 \mathrm{~Pa}, T_{0}=273.16 \mathrm{~K}, R_{3 \text {-ice }}=21.875$ $\mathrm{K}, R_{\text {3_liquid }}=17.269 \mathrm{~K}, R_{4 \text { _ice }}=7.66 \mathrm{~K}, R_{\text {4_liquid }}=35.86$ $\mathrm{K}$, with the "ice" constants being used below $-15^{\circ} \mathrm{C}$ and the "liquid" constants above freezing, and a gradual change, linear in $T$, from the ice constants to the liquid constants from the $-15^{\circ}$ to $0^{\circ} \mathrm{C}$ interval.

\section{3) Correction For Altitude OFFSETS BETWEen SITES}

The GPS and radiosonde sites are not collocated. For the comparisons we have selected pairs with separations of less than $50 \mathrm{~km}$, which will limit the effects of horizontal variations in atmospheric properties. It is necessary, however, to correct for vertical offsets, because the delay is a strong function of surface pressure or mass, which varies strongly with altitude. The largest altitude offsets are on the order of $1.7 \mathrm{~km}$, but most are much smaller.

We convert the GPS heights, which are geometric heights relative to the 1984 World Geodetic System (WGS84) ellipsoid, to a height relative to mean sea level, using the geoid 1996 Earth Gravitational Model (EGM96) (Lemoine et al. 1997). For GPS antenna levels above the lowermost radiosonde level, the properties at the antenna level are found by interpolation. For GPS antenna levels below the radiosonde launch level, the properties at the antenna level are estimated by extrap- 
olation, assuming a constant temperature lapse rate of $-0.00655 \mathrm{~K} \mathrm{~m}^{-1}$, and constant relative humidity at the value of the lowermost radiosonde level. The outcome in both cases is a transformed profile, valid from the GPS antenna level to the top of the radiosonde record. We do not attempt to shift or preserve the boundary layer structure, considering these errors are smaller than the assumptions that horizontal variations between the radiosonde and GPS site locations are negligible.

\section{4) INTEGRATION OF ZHD, ZWD, AND IWV OVER} THE TRANSFORMED RADIOSONDE PROFILES

ZTD is calculated as the sum of the hydrostatic and wet delays. Having access to both $T$ and $P$, we tested the precision of the Saastamoinen formula for the hydrostatic term that is based on an assumed average temperature profile.

In the integrations we do not use the geopotential heights provided in the radiosonde data that are based on certain assumptions for $g$. We take into consideration the height dependence of $g$ as

$$
g(z)=g_{s}\left(\frac{R_{s}}{R_{s}+z}\right)^{2},
$$

where $g_{s} \approx 9.780356 \mathrm{~m} \mathrm{~s}^{-2}\left(1+a_{1} \sin ^{2} \theta+a_{2} \sin ^{2} 2 \theta\right)$, $a_{1}=5.2885 \times 10^{-3}, a_{2}=-5.9 \times 10^{-6}$,

$$
R_{s} \approx \frac{R_{e}}{\sqrt{\left(R_{e} / R_{p}\right)^{2} \sin ^{2} \theta+\cos ^{2} \theta}},
$$

$R_{e} \approx 6378.1 \mathrm{~km}$, and the average Pole radius is $R_{p} \approx$ $R_{e}-21.5 \mathrm{~km}$ (Lide 1992). Using instead a constant value of $g$ will result in significant offsets. For $g=$ $9.80665 \mathrm{~m} \mathrm{~s}^{-2}$, such a bias is of the order $-5 \mathrm{~mm}$ at midlatitudes.

The relation between pressure and height is determined from the hydrostatic equation and the equation of state, yielding

$$
R_{d} T\left[1-q\left(\frac{1}{\varepsilon}-1\right)\right] \Delta \ln P=-g \Delta z .
$$

We use this to numerically calculate $g$ as a function of pressure, which is then used in Eq. (20) to find ZTD.

The integrated water vapor is calculated by numerical integration of Eq. (28) (which is exact for a hydrostatic atmosphere), once again taking into account the height variation of gravitational acceleration, and the difference in height between the GPS antenna and the radiosonde launch:

$$
\mathrm{IWV}=\int_{0}^{P_{\text {site }}} \frac{q}{g} d P .
$$

\section{5) Contribution From Above the MeAsured PROFILES}

The first term of the integral in Eq. (20), the hydrostatic component, includes a significant contribution from above the radiosonde profile. We derive an expression for that based on the assumptions of a hydrostatic atmosphere, constant temperature from the top of the radiosonde profile and above, and

$$
g(z)=g_{1}\left(\frac{R_{s}+z_{1}}{R_{s}+z_{1}+z}\right)^{2},
$$

which gives

$$
\begin{aligned}
\Delta \mathrm{ZHD} \approx \frac{k_{1} R_{d} P_{1}}{g_{1}}\{1 & +2 \frac{R_{d} T_{1}}{\left(R_{s}+z_{1}\right) g_{1}} \\
& \left.+2\left[\frac{R_{d} T_{1}}{\left(R_{s}+z_{1}\right) g_{1}}\right]^{2}\right\},
\end{aligned}
$$

with $T_{1}, g_{1}, z_{1}$, and $P_{1}$ being the values at the top of the known profile. Here, $\Delta \mathrm{ZHD}$ is added to the ZHD derived by numerical integration over the measured profile, yielding the total ZHD. The water vapor density is negligible above the top of the radiosonde profiles; therefore, no contribution is added to ZWD or IWV.

The results for the hydrostatic component, ZHD, are found to be very close to the results based on the Saastamoinen formula, with maximum systematic offsets of less than $0.5 \mathrm{~mm}$ of delay (Vedel 2001). The assumption of a constant temperature profile, as adopted by Saastamoinen, has no significant negative effect upon the estimate of ZHD, and the Saastamoinen formula can, in general, safely be used to estimate ZHD from the surface pressure data.

In the comparisons, it important to keep in mind that the radiosonde data also have errors associated with them. There are random errors in the temperature of $\pm 0.5^{\circ} \mathrm{C}$. The relative humidity sensor has errors of $\pm 2 \%-3 \%$. There are gross outliers that are removed to some extent by the screening employed above. More important, there may be systematic errors in the radiosonde data (Eskridge et al. 1995; Parker and Cox 1995). Historically, these have been due to differences in instrumentation, though instrumentation in western Europe has become standardized before the start of our experiment. Thermal lag and radiative characteristics of radiosonde thermometry affect the perceived pressure level at which temperature measurements are reported. These lag and radiative effects increase with height. Daytime radiation corrections are typically $-7^{\circ} \mathrm{C}$ between 100 and $30 \mathrm{hPa}$. Because these vary with solar radiation, then the time of launch, as well as balloon size and rate of ascent, can produce errors in the data. These errors show up as systematic differences between night and day radiosonde launches (WMO 1996). Systematic differences in albedo (over ocean surfaces or clouds) also increase errors in the radiative corrections. 
TABLE 2. GPS ZTD-radiosonde comparison table. Comparison of the zenith tropospheric delay derived from the GPS measurements with those integrated from the radiosonde profiles. The column Dis gives the horizontal distance between the radiosonde launch site and the GPS antenna; $d z$ is the difference in altitude between the GPS antenna and the radiosonde launch site.

\begin{tabular}{|c|c|c|c|c|c|c|c|c|}
\hline GPS name & Radiosonde ID & Dis $(\mathrm{km})$ & $d z(\mathrm{~m})$ & $\begin{array}{l}\text { GPS altitude } \\
(\mathrm{m})\end{array}$ & Bias (mm) & Std dev (mm) & $\begin{array}{l}\text { No. of data } \\
\text { points }\end{array}$ & Correlation \\
\hline ACOR & 08001 & 2 & -52 & 15 & 6.7 & 11.7 & 674 & 0.958 \\
\hline AJAC & 07761 & 3 & 45 & 54 & 6.9 & 11.5 & 47 & 0.949 \\
\hline BRST & 07110 & 10 & -74 & 21 & 11.9 & 11.7 & 221 & 0.966 \\
\hline CAGL & 16560 & 15 & 187 & 192 & 14.3 & 13.3 & 2487 & 0.953 \\
\hline CART & 08430 & 48 & -19 & 43 & 12.6 & 18.1 & 576 & 0.901 \\
\hline CASC & 08579 & 26 & -82 & 23 & 7.9 & 14.7 & 531 & 0.947 \\
\hline GRAZ & 11240 & 9 & 144 & 491 & -4.1 & 7.6 & 418 & 0.987 \\
\hline HFLK & 11120 & 6 & 1743 & 2336 & 1.6 & 6.6 & 457 & 0.980 \\
\hline KOSG & 06260 & 44 & 49 & 53 & 2.9 & 10.6 & 2946 & 0.976 \\
\hline MEDI & 16144 & 15 & -1 & 10 & 3.3 & 9.2 & 1083 & 0.984 \\
\hline OBER & 10868 & 27 & 107 & 596 & 6.1 & 8.9 & 1291 & 0.980 \\
\hline SJDV & 07481 & 35 & 142 & 382 & 5.2 & 10.8 & 1192 & 0.969 \\
\hline VILL & 08221 & 32 & -38 & 595 & 9.1 & 11.3 & 906 & 0.952 \\
\hline ZIMM & 06610 & 40 & 417 & 908 & 6.1 & 11.5 & 1427 & 0.961 \\
\hline ALL & - & - & - & - & 6.8 & 12.3 & 14256 & 0.996 \\
\hline
\end{tabular}

Data-processing algorithms for treating humidity measurements below 20\% and those made at low ambient temperatures have been inconsistently applied (Elliott and Gaffen 1991; Elliott 1993; Wade 1994). Liljegren et al. (1999) have shown that the age of the radiosonde at the time of launch has contributed to biases in the humidity measurements, which led to differences up to $2 \mathrm{~mm}$ of integrated water vapor, if uncorrected. These possible error sources will be considered in later discussions of the comparison results.

\section{b. Results of the GPS-radiosonde comparison}

We compared GPS and radiosonde-derived ZTD calculated at the 14 GPS stations for which we have radiosonde profiles nearby (Table 2, Fig. 1). Because of the uncertainty between the atmospheric state at the two sites, which may be separated by as much as $50 \mathrm{~km}$, there is a limit to the level of agreement that can be expected. However, the extremely low scatter of the residuals shows very good agreement of the two datasets.

Table 2 and Fig. 6 show the result of the comparison,

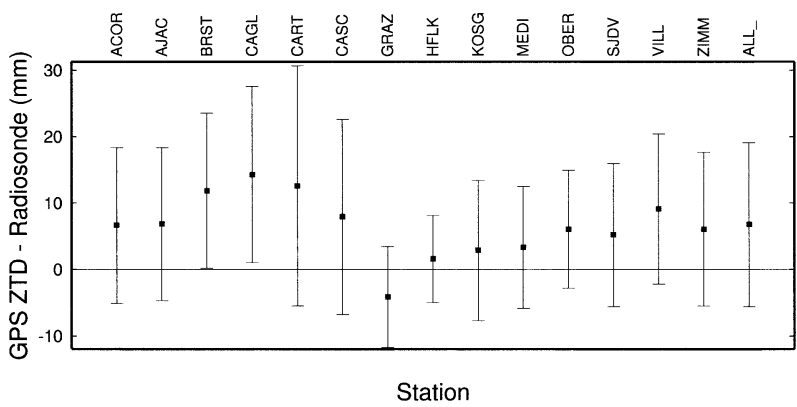

FIG. 6. Avg and std dev of the difference between GPS ZTD and radiosonde ZTD for each station. Stations are sorted alphabetically. Avg and std dev for all stations together are shown by ALL_. There is only 1 month of data for AJAC. together with the horizontal separation and difference in altitude between the GPS and the radiosonde launch sites. The standard deviation of the residuals is \pm 12.3 $\mathrm{mm}$, which is the equivalent of approximately $2 \mathrm{~kg} \mathrm{~m}^{-2}$ of integrated water vapor error. Nine sites show small biases, less than $7 \mathrm{~mm}$ of delay, that are systematically positive (GPS ZTD greater than RS ZTD). The standard deviation for the best sites is near the level obtained in the comparisons carried out between different GPS processing centers, $\pm 7 \mathrm{~mm}$, indicating that the agreement is at the limit of the precision of the GPS technique. The correlation coefficients between the datasets are very high, greater than 0.9 at all sites (Table 2).

There is no correlation of the bias with the altitude difference between the radiosonde launch site and the GPS site (Table 2). This demonstrates that the height correction applied before integration of the radiosonde profiles was successful in removing the first-order effects of this difference, even for sites with vertical offsets as large as $1700 \mathrm{~m}$. If uncorrected, the difference in ZTD would be on the order of $0.28 \mathrm{~mm}$ of delay per meter of height difference. The sites where large vertical corrections are necessary tend to be sites in mountainous regions where, because of the high altitude, the integrated water vapor is generally lower. NWP algorithms must take into account the vertical offset between the GPS observation altitude and the model orography before the data can be assimilated. The standard deviation of the radiosonde residual and the bias show a dependence on the absolute site altitude, with the lowestaltitude stations having much higher residuals. The lowaltitude stations also have the highest humidity, and the horizontal variability between the GPS and radiosonde site is probably greater.

Figure 2 displays an example of the 1-yr time series and the GPS-radiosonde residuals. There is a strong seasonal signal that is visible in the residual time series, with the standard deviation significantly higher in the 
summer than in the winter. The mean and the standard deviation of the residuals are calculated for each station for each month (Figs. 7a,b). The standard deviation increases from about $7 \mathrm{~mm}$ of ZTD in the winter to about $15 \mathrm{~mm}$ of ZTD in the summer. A few sites, such as CAGL and CART, have exceptionally high residuals. The level of agreement of $7 \mathrm{~mm}$ of ZTD for most sites during the winter months indicates that the measurements are consistent with the precision level of the GPS ZTD measurements.

The observation of an increase in standard deviation of the residuals with increasing humidity could have several possible origins, either in the GPS ZTD data, the radiosonde data, or the natural variability of the water vapor fields themselves. The summertime standard deviation of $15 \mathrm{~mm}$ of ZTD would correspond to an error of approximately $2-3 \mathrm{~kg} \mathrm{~m}^{-2}$ of integrated water vapor, or $6 \%-9 \%$ of typical values of integrated water vapor for these stations. This is significantly higher than the specified random error level of the radiosonde humidity sensors, which is nominally less than $5 \%$. The most likely source for this seasonally dependent error is the spatial variability of the humidity fields. During periods of high humidity, the distribution of water vapor is more heterogeneous and, thus, more likely to have significant lateral variations in the structure that would lead to higher disagreement between the GPS and radiosonde measurement sites.

In terms of integrated water vapor, the comparison with radiosonde measurements shows a bias of $0.4 \mathrm{~kg}$ $\mathrm{m}^{-2}$ and a standard deviation of $2.3 \mathrm{~kg} \mathrm{~m}^{-2}$. The level of agreement is consistent with previous studies (Bevis et al. 1992; Rocken et al. 1995; Duan et al. 1996; Emardson et al. 1998; Tregoning et al. 1998), and slightly better in terms of bias. The better agreement could be caused by the fact that, having processed a very long time series, our estimates of the bias is less sensitive to transient signals in the humidity.

The distribution of the residuals is bimodal. For example, at MEDI, the radiosondes launched at noon show a bias of $6.5 \mathrm{~mm}$, while the ones launched at midnight show a bias of $0.3 \mathrm{~mm}$ (Fig. 8). There is no significant difference in the standard deviation of 8.1 versus 8.9 $\mathrm{mm}$. This is true for the entire dataset. Furthermore, the midday bias varies seasonally, but the midnight bias is relatively constant over the year (Figs. 7c and 7d). One cannot argue that the biases are higher during the day because of higher humidity and higher variability, because we show that the mean GPS ZTD is the same during the day and night (Fig. 7e). This indicates that the seasonal biases between the GPS and the radiosondes seen in Fig. 7 are most likely due to the daynight humidity bias present in the radiosonde measurement, rather than in a humidity bias related to the GPS measurement. The fact that this day-night radiosonde bias scales with humidity produces the seasonal dependence. The day-night bias of radiosondes has been documented in simultaneous flight tests comparing many standard radiosondes with a reference radiosonde (WMO 1996). Our results indicate the effects of these biases on the humidity measurements. On the other hand, we have no basis for distinguishing the origin of the small positive bias of GPS ZTD relative to the midnight radiosonde data, which could equally likely be attributed to a GPS or a radiosonde error source. The standard deviation of the GPS minus radiosonde ZTD has the same seasonal variation both in the midday and the midnight radiosonde comparisons.

\section{Comparison with the DMI HIRLAM NWP model}

We wish to compare modeled versus observed ZTD at higher temporal resolution than the typical 6-h interval, typically available from archived analysis fields. Therefore, we implemented a version of the operational HIRLAM running at the DMI specifically for the MAGIC project that was centered on the western Mediterranean. The model has a resolution of $0.3^{\circ}$ with 31 vertical levels. The region extends from $-33^{\circ}$ to $39.3^{\circ}$ longitude and from $24^{\circ}$ to $55.5^{\circ}$ latitude. Analyses (assimilation of new observational data without including the GPS ZTD data) are made every $6 \mathrm{~h}$ (0000, 0600, 1200, 1800 UTC). The maximum forecast length for the data provided are $6 \mathrm{~h}$. The boundary fields come from the European Centre for Medium-Range Weather Forecasts (ECMWF). Except for the limits of the region and the necessary modifications to extract the data for the MAGIC project, the model we run is the same as the operational model being used at DMI.

We calculate the ZTD values from the model fields of HIRLAM, extracting the data at the locations of the GPS points every $15 \mathrm{~min}$ from the 6- and 12-h forecast run. The properties of the atmosphere above each GPS site are calculated first by a horizontal interpolation within the HIRLAM grid. Second, a vertical transformation is applied to the atmospheric profile at the GPS site to allow for the offset in altitude between the HIRLAM surface and the real surface (the specified altitude of the GPS antenna). Here, we adopt a method described by Majewski (1985), which is widely used for mapping meteorological data from one model grid to another. After the vertical shift of the atmospheric profile, we derive estimates of the 2-m temperature and humidity. Then, we carry out a numerical integration of the model fields to estimate ZTD, ZWD, and IWV at the GPS antenna level. The integration uses the same methodology as that used for the radiosonde profiles.

The comparison statistics between the ZTD values extracted from HIRLAM and those derived from the GPS analysis are shown in Table 3 and Fig. 9. The bias in ZTD is $3.4 \mathrm{~mm}$, with a standard deviation of 18.1 $\mathrm{mm}$. The equivalent error in terms of IWV, assuming most error is associated with the wet component and not the hydrostatic component, would correspond to a $0.5 \mathrm{~kg} \mathrm{~m}^{-2}$ bias and $3 \mathrm{~kg} \mathrm{~m}^{-2}$ standard deviation. These 


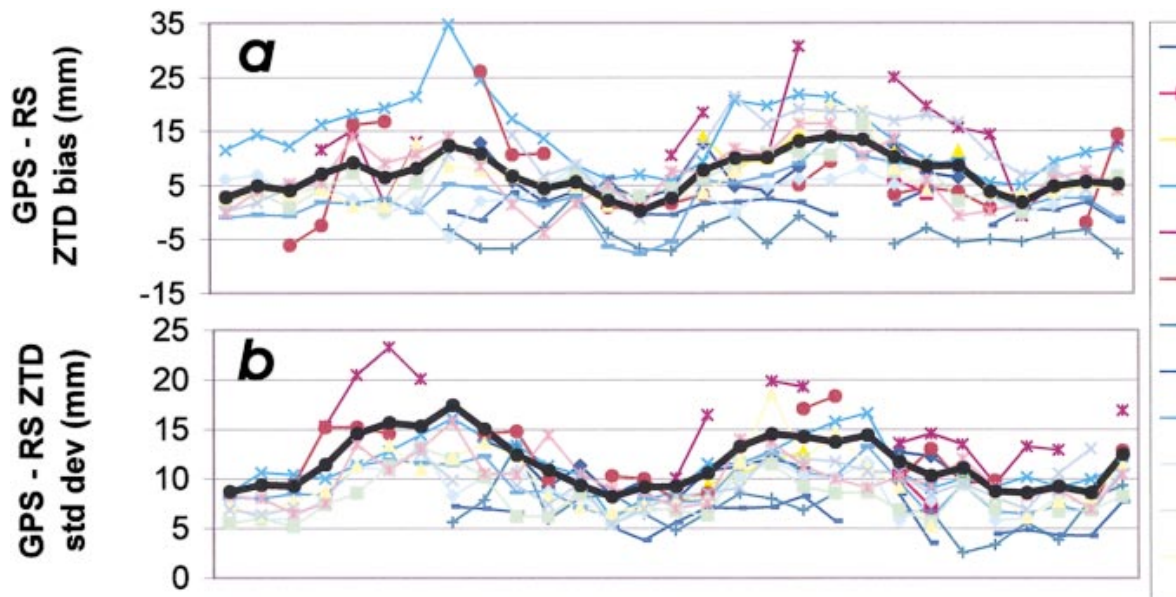

- ACOR
- AJAC
- BRST
- - CAGL
$*$ CART
- CASC
- GRAZ
- HFLK
- KOSG
MEDI
OBER
SJDV
- VILL
- ZIMM
- ALL

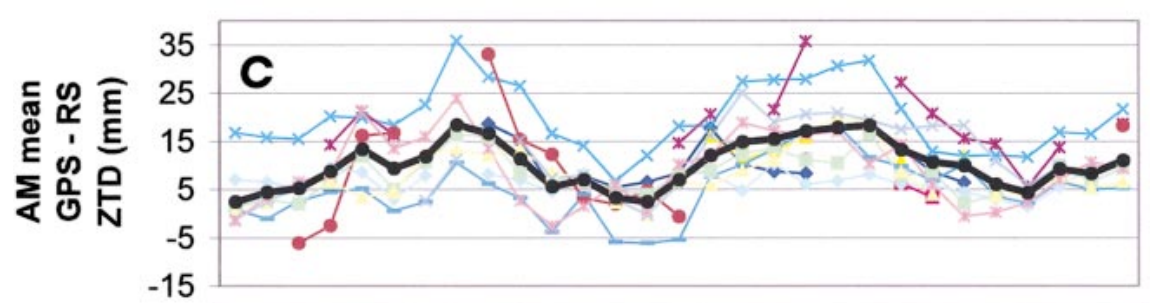

$\rightarrow A_{-}$
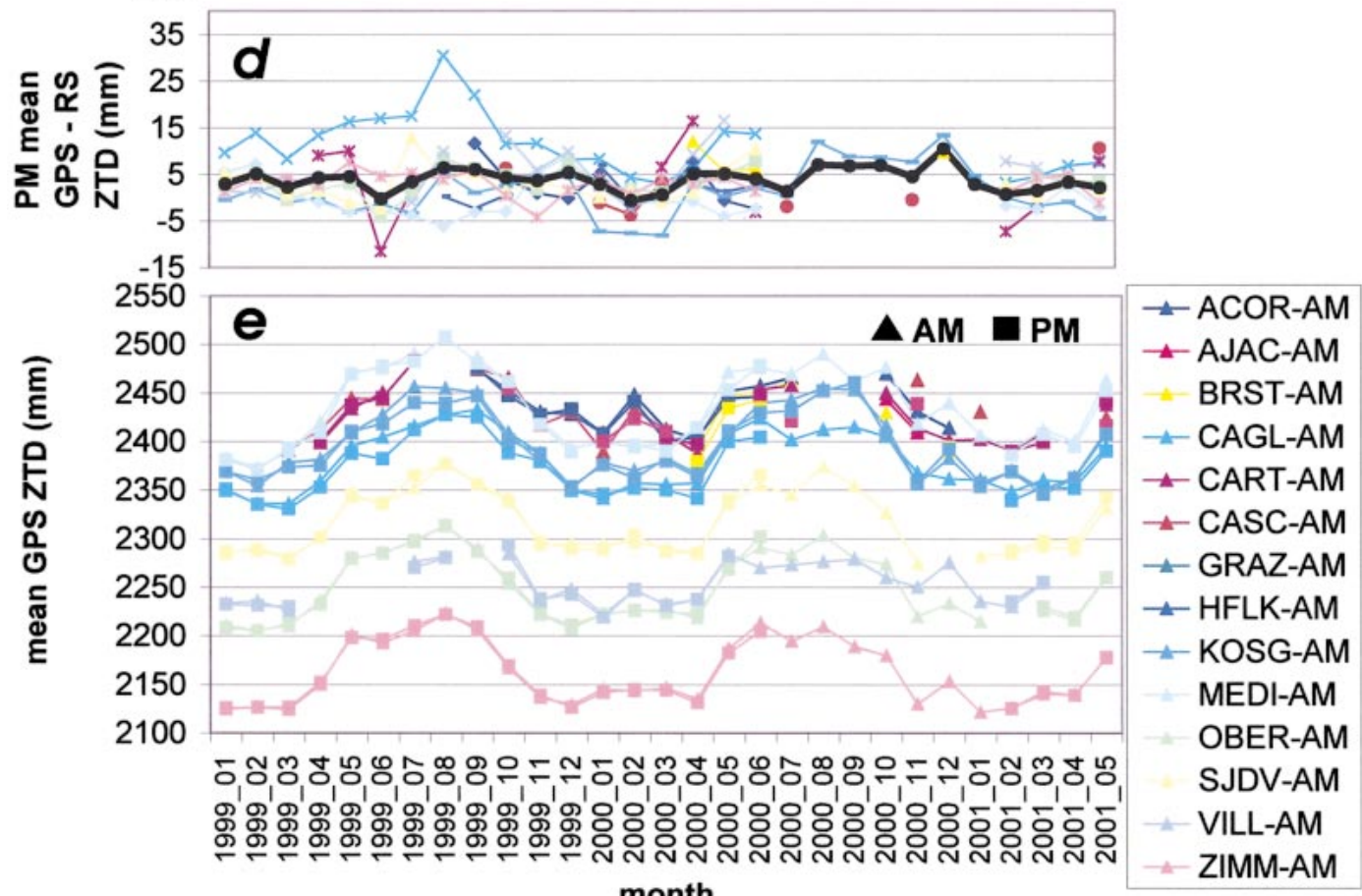

FIG. 7. (a) Time-dependent behavior of the mean GPS-radiosonde ZTD difference over a 2.5-yr time period, (b) std dev of the GPS-radiosonde ZTD difference, (c) mean GPS-radiosonde ZTD residuals for midday radiosonde launches, (d) mean GPS-radiosonde ZTD residuals for midnight radiosonde launches, and (e) mean GPS ZTD values for each site with midday launches (triangles) and midnight launches (squares). The mean residuals are much lower for midnight launches and have no annual variation even though the mean humidity (represented by mean GPS ZTD) is the same for midday and midnight. 


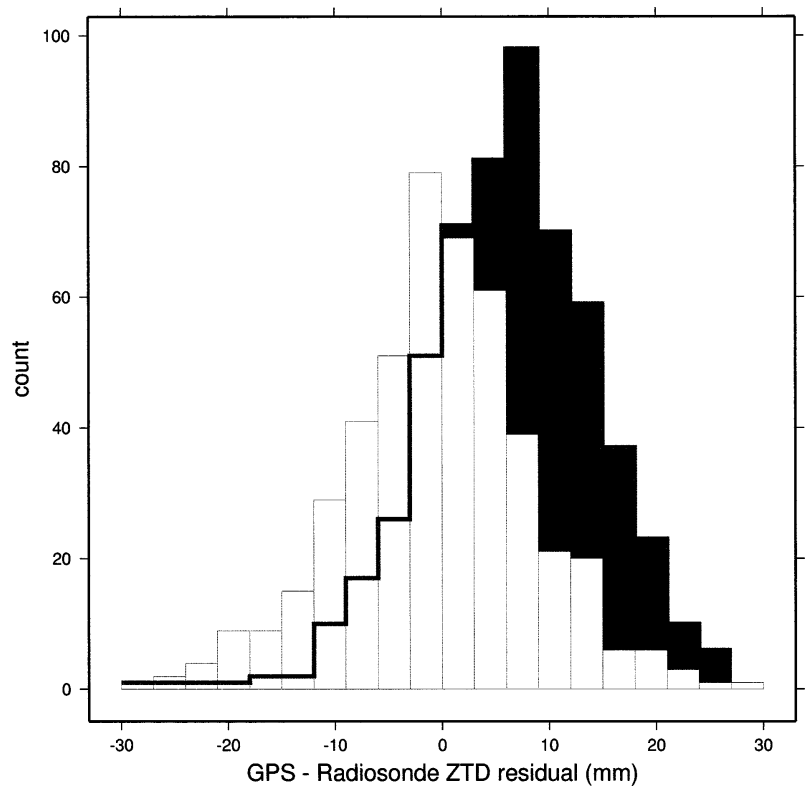

FIG. 8. Histogram of GPS-radiosonde ZTD residuals for station MEDI. Dark curve is midday launches with mean of 6.5 and std dev of $8.1 \mathrm{~mm}$ of ZTD; light curve is midnight launches with mean of 0.3 and std dev of $8.9 \mathrm{~mm}$ of ZTD.

results are close to those obtained by Kuo et al. (1996) and Yang et al. (1999), which are on the order of a 0.5 $\mathrm{kg} \mathrm{m}^{-2}$ bias and $2.5 \mathrm{~kg} \mathrm{~m}^{-2} \mathrm{rms}$. The bias and standard deviation for the 6 -h forecast is not significantly different than the 12-h forecast.

The correlation between the GPS and HIRLAM ZTD is high, but it is lower than that for the radiosonde ZTD (Table 3). The correlation decreases for lower-latitude sites (Fig. 10).

Figure 11 shows that the agreement between GPS and HIRLAM increases when the altitude of the site increases, contrary to what might be expected, given the resolution of the model orography. This is consistent, however, with the observation that the agreement is better for low humidity and, hence, low-humidity variability situations. It is also consistent with the GPSradiosonde residuals. The bias is systematically positive for all but three stations.

There is a strong correlation between the standard deviation of the GPS-HIRLAM residuals and the latitude of the site (Fig. 11). This correlation is not obvious in the radiosonde comparison, and the standard deviation is not nearly as high as for the GPS-HIRLAM comparison. This, and also the fact that the correlation decreases at lower latitudes, indicates that HIRLAM does not model the moisture as well at low latitudes. This is not unexpected for the implementation of HIRLAM at the Danish Meteorological Institute, which has been tuned to run within higher-latitude limits. It could also be the case that HIRLAM forecasts better for high latitudes where dynamical forcing dominates, rather than in the Mediterranean where the evolution of het- erogeneous high-humidity fields may be more dominated by physics. It could also indicate that the scale of variability is smaller-or has higher temporal variability at low latitudes, than the HIRLAM resolution is adapted to model. This also can be seen in Fig. 12 where sites where GPS and HIRLAM agree less well are also sites that have a high variance rate in the structure function. In any case, the humidity information provided by GPS would be expected to have the greatest impact for assimilation in lower latitudes, based on this observation.

There is no obvious correlation between the HIRLAM-GPS bias and standard deviation and the proximity of a radiosonde launch site. The agreement might be expected to be better because the humidity information in HIRLAM derives almost exclusively from the radiosonde observations. However, that is not the case. This may be indicative that the timescale of humidity variation is much shorter than the typical 6- or 12-h radiosonde observation interval.

Once again, there is a strong seasonal signal in the residual time series, with the standard deviation significantly higher in the summer than in the winter. The mean and the standard deviation of the residuals are calculated for each station for each month. The standard deviation increases from about $12 \mathrm{~mm}$ of ZTD in the winter to about $24 \mathrm{~mm}$ of ZTD in the summer. All sites are well above the 7-mm level of precision of the GPS ZTD measurements. The mean across the network is around $5 \mathrm{~mm}$ of ZTD. In contrast to the GPS-radiosonde comparison, this mean does not vary between noon and midnight measurements, and is very similar to the midnight mean GPS-radiosonde comparison. There is no clear dependence of the mean GPS-HIRLAM differences on the season. Because the level is similar in both comparisons, we suspect that the relatively stable 5-mmlevel positive bias may be a characteristic of the GPS observations, though the source of this bias is unknown.

\section{Error correlations}

Part of the GPS ZTD data assimilation methodology development that is undertaken in the MAGIC project requires the characterization of the errors, and, in particular, the investigation into the horizontal correlation structure of the data errors. The GPS-radiosonde residuals are calculated at each epoch for a given pair of GPS stations, and then the correlation coefficient between the residuals is calculated. The correlation coefficient is plotted as a function of the distance separating the pair of GPS stations in Fig. 13. This is done for each pair of stations that have nearby radiosonde data. The GPS-radiosonde residual can be considered as an estimate of the error, and for the purposes of assimilation into NWP models, it would be preferable that the errors at one GPS site were not correlated with another GPS site. However, there is some indication that the correlation coefficient is higher for GPS stations pairs that are closer together. The correlation coefficient 
TABLE 3. Comparison of the zenith tropospheric delay derived from the GPS measurements with those calculated from the HIRLAM 6-h forecasts. The Alt is the altitude of the GPS antenna relative to mean sea level, and $d z$ is the difference between the GPS antenna altitude and HIRLAM orography. This height difference is taken into account by an interpolation or extrapolation of the model fields.

\begin{tabular}{|c|c|c|c|c|c|c|c|c|}
\hline Station & Lat $\left({ }^{\circ} \mathrm{N}\right)$ & Lon $\left({ }^{\circ} \mathrm{E}\right)$ & Alt (m) & $d z(\mathrm{~m})$ & $\begin{array}{l}\text { ZTD bias } \\
\quad(\mathrm{mm})\end{array}$ & $\begin{array}{l}\text { Std dev } \\
(\mathrm{mm})\end{array}$ & $\begin{array}{l}\text { No. of data } \\
\text { points }\end{array}$ & Correlation \\
\hline ACOR & 43.36438 & -8.39893 & 14.9 & -120.9 & 1.7 & 19.8 & 16153 & 0.88 \\
\hline ALAC & 38.33892 & -0.48123 & 14.3 & -215.9 & 6.7 & 19.9 & 19417 & 0.89 \\
\hline AQUI & 42.36884 & 13.35034 & 667.2 & -419.4 & 0.7 & 16.8 & 15661 & 0.90 \\
\hline BELL & 41.59962 & 1.40114 & 803.6 & 309.0 & 3.8 & 17.0 & 29230 & 0.92 \\
\hline BZRG & 46.49902 & 11.33680 & 279.5 & -1162.4 & -2.6 & 19.2 & 29856 & 0.94 \\
\hline CAGL & 39.13591 & 8.97275 & 191.8 & 57.1 & 5.1 & 19.3 & 32138 & 0.89 \\
\hline CART & 37.58675 & -1.01204 & 43.5 & -5.0 & 5.4 & 20.0 & 13562 & 0.88 \\
\hline CASC & 38.69341 & -9.41852 & 22.8 & -8.6 & 0.8 & 24.4 & 23042 & 0.82 \\
\hline CHAT & 45.30414 & 6.35856 & 799.3 & -959.4 & 3.6 & 17.7 & 16969 & 0.90 \\
\hline COSE & 39.20142 & 16.31041 & 618.2 & -11.0 & 5.6 & 22.6 & 10173 & 0.81 \\
\hline CREU & 42.31884 & 3.31560 & 83.8 & 65.8 & 5.4 & 19.9 & 26521 & 0.92 \\
\hline EBRE & 40.82089 & 0.49236 & 57.7 & -239.1 & 2.8 & 21.6 & 31037 & 0.92 \\
\hline ESCO & 42.69357 & 0.97566 & 2455.2 & 916.8 & 3.5 & 11.3 & 18749 & 0.93 \\
\hline FCLZ & 45.64300 & 5.98568 & 1308.7 & 542.9 & 6.4 & 12.6 & 29519 & 0.95 \\
\hline GENO & 44.41939 & 8.92114 & 110.8 & -164.5 & 5.2 & 20.1 & 33185 & 0.93 \\
\hline GINA & 43.67572 & 5.78698 & 331.5 & -128.9 & 3.4 & 16.7 & 31161 & 0.94 \\
\hline GRAS & 43.75474 & 6.92057 & 1269.4 & 561.3 & 2.0 & 15.0 & 26093 & 0.94 \\
\hline GRAZ & 47.06713 & 15.49348 & 490.9 & -79.8 & 2.1 & 13.8 & 31524 & 0.96 \\
\hline HFLK & 47.31290 & 11.38609 & 2336.0 & 809.5 & 2.9 & 9.7 & 30175 & 0.96 \\
\hline KOSG & 52.17843 & 5.80964 & 53.5 & 36.1 & 1.1 & 12.8 & 32264 & 0.97 \\
\hline LAMP & 35.49977 & 12.60566 & 19.9 & 19.4 & 8.6 & 25.0 & 27847 & 0.81 \\
\hline LLIV & 42.47813 & 1.97305 & 1415.8 & -121.7 & 6.7 & 13.9 & 16913 & 0.93 \\
\hline MAHO & 39.89736 & 4.26850 & 50.1 & 40.2 & -4.0 & 23.1 & 9613 & 0.81 \\
\hline MARS & 43.27877 & 5.35379 & 12.4 & -93.8 & 1.4 & 18.7 & 24441 & 0.92 \\
\hline MAS1 & 27.76374 & -15.63328 & 155.4 & 35.8 & 0.1 & 24.2 & 22562 & 0.78 \\
\hline MATE & 40.64913 & 16.70446 & 490.0 & 265.7 & 1.0 & 17.8 & 32231 & 0.91 \\
\hline MEDI & 44.51996 & 11.64681 & 9.7 & -76.0 & 1.3 & 17.2 & 32835 & 0.95 \\
\hline MELI & 35.28990 & -2.93924 & 11.5 & -63.3 & -3.1 & 23.0 & 12404 & 0.82 \\
\hline $\mathrm{MICH}$ & 43.92416 & 5.71735 & 577.4 & -30.2 & 3.3 & 15.4 & 30659 & 0.94 \\
\hline MODA & 45.21378 & 6.71008 & 1129.1 & -1009.9 & 7.2 & 16.9 & 30425 & 0.92 \\
\hline MTPL & 43.63744 & 3.86484 & 91.3 & -15.6 & 11.1 & 17.8 & 14446 & 0.93 \\
\hline NOTO & 36.87611 & 14.98981 & 85.2 & -77.1 & 5.8 & 25.7 & 26681 & 0.83 \\
\hline OBER & 48.08617 & 11.27987 & 595.7 & 18.5 & 3.6 & 12.9 & 32787 & 0.96 \\
\hline SFER & 36.46434 & -6.20565 & 39.5 & 12.6 & 1.9 & 21.8 & 30476 & 0.82 \\
\hline SJDV & 45.87908 & 4.67657 & 382.4 & 20.9 & 3.7 & 14.8 & 28720 & 0.94 \\
\hline TORI & 45.06337 & 7.66128 & 262.7 & -151.0 & 2.4 & 17.2 & 30864 & 0.96 \\
\hline TOUL & 43.56077 & 1.48076 & 158.6 & -7.6 & 3.6 & 17.8 & 27669 & 0.93 \\
\hline UNPG & 43.11939 & 12.35570 & 303.4 & -93.6 & 8.5 & 17.7 & 22641 & 0.92 \\
\hline UPAD & 45.40672 & 11.87793 & 39.4 & 16.7 & 0.3 & 15.9 & 26553 & 0.96 \\
\hline VILL & 40.44359 & -3.95198 & 595.3 & -174.6 & 0.6 & 17.4 & 31627 & 0.89 \\
\hline WTZR & 49.14420 & 12.87891 & 619.2 & 72.4 & 2.5 & 12.2 & 32741 & 0.96 \\
\hline ZIMM & 46.87710 & 7.46528 & 907.5 & 22.2 & 7.7 & 13.2 & 31719 & 0.95 \\
\hline OVERALL & - & - & - & - & 3.4 & 18.1 & 1073283 & 0.99 \\
\hline
\end{tabular}

is less than 0.3 at greater than $600-\mathrm{km}$ separation, but there are not enough data from the 14 GPS stations to determine with confidence the distance dependence of the error correlation at short distances.

The same is done for the GPS-HIRLAM 0-6-h forecast residuals (Fig. 14). Once again, the residuals are calculated at each time for a given pair of GPS stations, and the correlation coefficient between the residuals is calculated. The correlation coefficients are plotted as crosses in Fig. 14 as a function of the distance separating the pair of GPS stations. Here there are enough data to average the correlation coefficients over bins in $25-\mathrm{km}$ distance ranges, shown as circles. The correlation drops off quickly and on average is below 0.3 at less than $200-\mathrm{km}$ distance, but there are a significant number of station pairs that have a correlation greater than 0.3 between 200 and $400 \mathrm{~km}$. An $e$-folding scale on the order of $200 \mathrm{~km}$ is not unrealistic for error correlations near the ground for HIRLAM variables, but further studies are needed to clarify how much of the correlation can be attributed to the GPS data.

\section{Discussion}

In this section we discuss the implications the error characteristics of the data have for ongoing and future assimilation tests. Then, we discuss the main problems in handling the data: carrying out the processing within a short delay and handling the relatively large biases that vary significantly over the timescale of 1 month. 


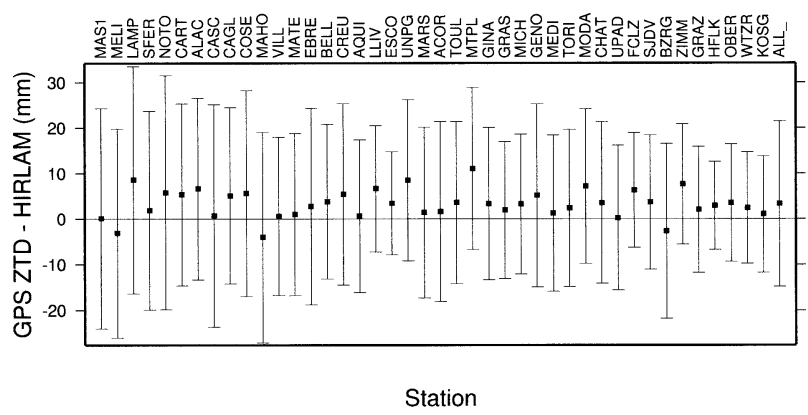

FIG. 9. Avg and std dev of the difference between GPS ZTD and HIRLAM ZTD for each station. Stations are sorted by latitude with latitude increasing to the right. Note the trend for smaller std dev for higher-latitude sites. Avg and std dev for data from all stations together are shown by ALL_.

Last, we review the possible remaining sources of error that merit further investigation in both the radiosonde and GPS dataset.

The objective of this study was to investigate the potential for improving initial humidity fields in NWP models based on the available quality of the data. The outlook is promising because of the better agreement of the GPS ZTD data with the radiosonde data than with the HIRLAM fields. The GPS-HIRLAM residuals have a standard deviation of $18 \mathrm{~mm}$ of ZTD. To put this in context, the standard deviation of the ZTD time series with a sinusoidal yearly signal removed is $33 \mathrm{~mm}$, and the standard deviation of the ZTD minus an estimated ZTD based on a linear regression on the surface humidity is $23 \mathrm{~mm}$. Therefore, there is on the order of 24 $\mathrm{mm}$ of variation in the ZTD data due to the signal from upper-level humidity. The best estimate of the precision of the GPS data is $12 \mathrm{~mm}$ based on the radiosonde comparison. Thus, there is a potential additional variance reduction of at least $55 \%$ to be achieved in assimilating the GPS ZTD data as compared with the $40 \%$ variance reduction in going from surface predictions of total column humidity to the HIRLAM-modeled values. An important further benefit from GPS ground observations is the order-of-magnitude increase in reporting frequency in comparison with present observations of the upper-air humidity field: observations are available at fractions of hours as compared with the typical launch frequency of $12 \mathrm{~h}$ for radiosondes. Likewise they will increase the spatial resolution of the upper-air humidity observing network, which is currently poorer than for most other important atmospheric properties.

The GPS data processing strategy has been modified to run in near-real time (NRT) (Ge et al. 2000). In operational weather prediction, meteorological observations are typically assimilated every $6 \mathrm{~h}$. With the new generation of meteorological satellite observations provided at intervals of $1 \mathrm{~h} 40 \mathrm{~min}$ and the new generation of $4 \mathrm{D}$ variational models, which can assimilate observations made at any time rather than the historically chosen 6-h intervals, the reporting delay currently required by the World Meteorological Organization (WMO 1996) is approximately $1 \mathrm{~h} 45 \mathrm{~min}$ at the latest. We have compared the NRT estimates with the precise postprocessed estimates of ZTD from 1 month of data at 15 sites in western Europe, and there is a negligible bias and a standard deviation of less than $6.1 \mathrm{~mm}$ in the ZTD estimates in comparison with using IGS final orbits. This is less than the 7-mm level of precision of GPS-derived ZTD from IGS final orbits, based on the

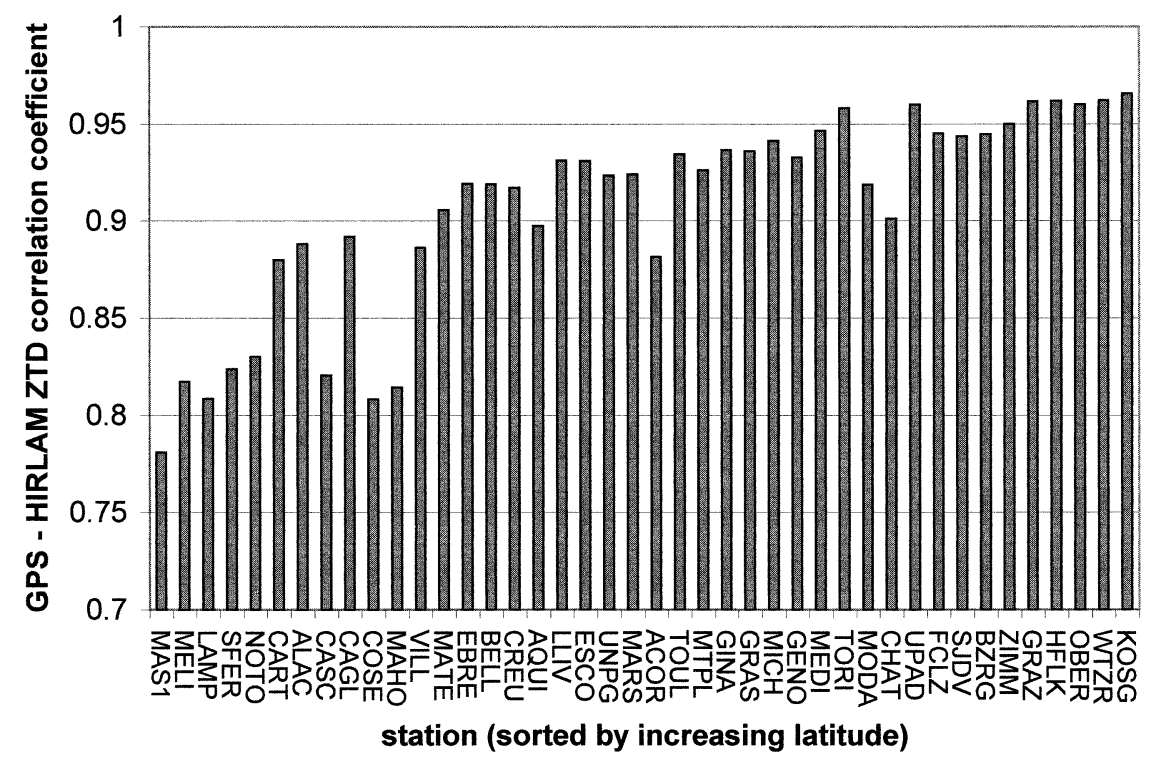

FIG. 10. Magnitude of the correlation coefficient between the GPS ZTD and HIRLAM ZTD time series for each site, with sites sorted by increasing geographic latitude. The correlation decreases with decreasing latitude. 

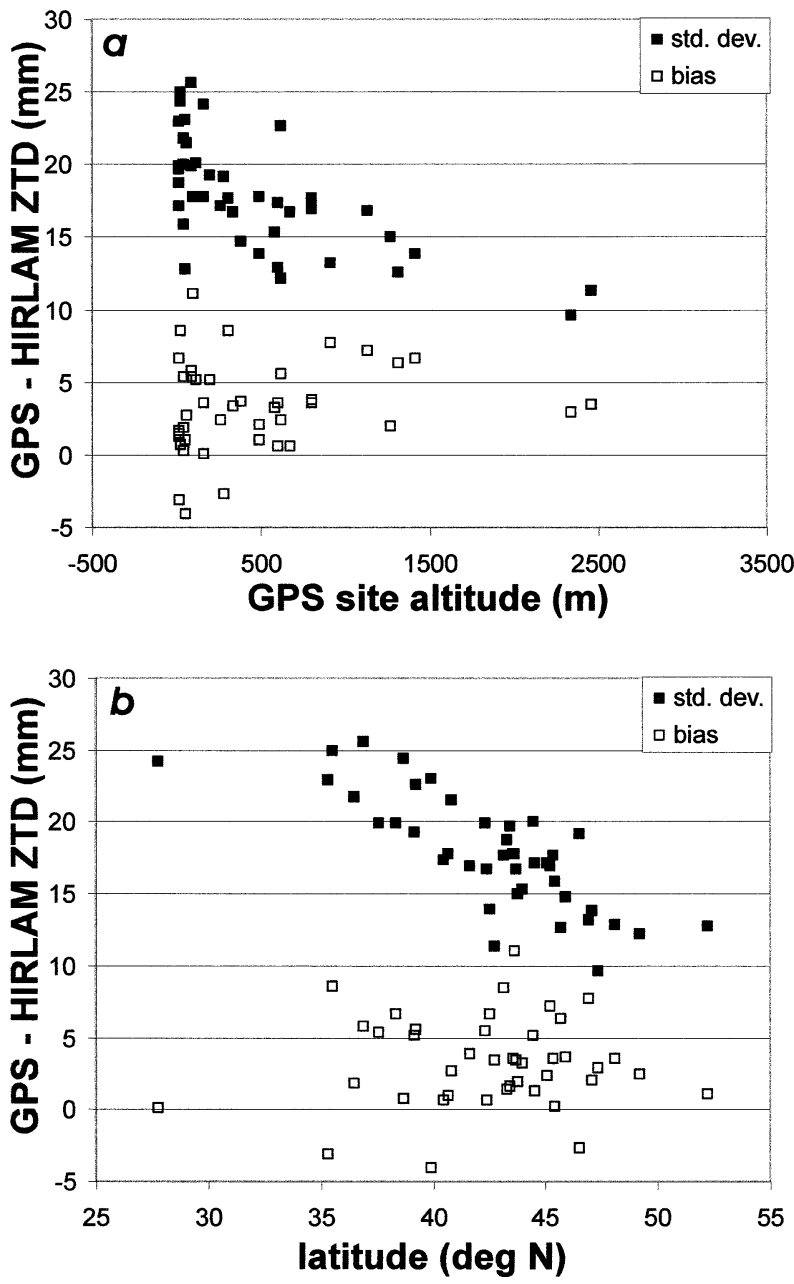

FIG. 11. (a) The std dev of the difference between the GPS ZTD and the HIRLAM 6-h forecast decreases as altitude increases. The model is successful in reproducing the observed ZTD in mountainous, high-altitude terrain, even though the HIRLAM model orography is of very low resolution. (b) The std dev decreases as latitude increases, indicating dynamics are better modeled by HIRLAM in higher-latitude regions than in the Mediterranean.

intercomparisons of results from different software. While future operational assimilation would use the NRT estimates of ZTD, currently the number of stations whose data are available in NRT in Europe is not sufficient to carry out a detailed analysis. Therefore, the results presented in this paper were the postprocessed estimates of ZTD derived from the final IGS orbits with a 2-week delay. The total number of sites is rapidly approaching the number of radiosonde sites, 51 GPS sites as compared with 123 radiosonde sites, used in this study. The installation of new GPS stations is increasing at a rapid rate in Europe. This steady increase in the quantity of available data in comparison with other observations will soon provide sufficient weight for definitive NRT NWP impact tests.

Throughout the comparisons that we carried out, correlations exist that indicate that the bias and the standard

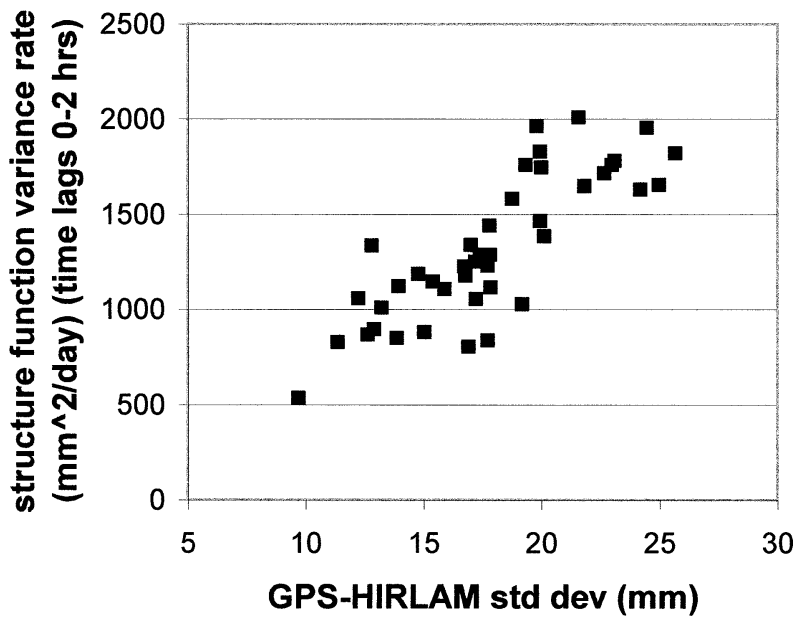

FIG. 12. The std dev of the GPS-HIRLAM ZTD residuals increases as the ZTD structure function variance rate for each site increases. The variance rate gives an indication of the variance of ZTD for short time lags. A high variance rate means high-amplitude rapid temporal variations in $\mathrm{ZTD}$

deviation increase with increasing humidity. This is particularly obvious in the monthly comparisons where there is a higher standard deviation for higher-humidity summer months. It is also clear in the elevation dependence of the standard deviation, where low-elevation stations that are closer to sea level have higher humidity and a high standard deviation of GPS-radiosonde residuals. High-altitude stations, even though there may be a large topographic height correction applied, generally have much lower biases and standard deviations because they tend to have less overall humidity. This also shows up in the comparisons where the standard deviation of the residuals increases with lower-latitude stations, consistent with higher averages of water vapor content at lower latitudes.

Through the comparisons, we demonstrated that there is a significantly poorer fit of HIRLAM to the GPS data as latitude decreases and as mean integrated water vapor increases. This indicates that there is a high potential benefit for improving model forecasts in the Mediterranean region, in particular. The low-latitude sea level sites, with high humidity due to their proximity to the warm Mediterranean Sea, are particularly poorly modeled. This will be tested in future assimilation studies.

The most important drawback to the current dataset is the relatively large biases we have shown in the comparisons. There is some indication that the errors are not random and independent at the level of $1 \mathrm{~kg} \mathrm{~m}^{-2}$ of water vapor (about $6.4 \mathrm{~mm}$ ZTD). The biases at three individual stations in the radiosonde comparison exceed the equivalent of $1 \mathrm{~kg} \mathrm{~m}^{-2}$ in water vapor. This does not reduce the potential impact of the GPS ZTD data, if the biases are understood well enough to be removed. For example, if they are constant over some temporal scale at each site, then the data can be empirically corrected and assimilated without serious complications. 


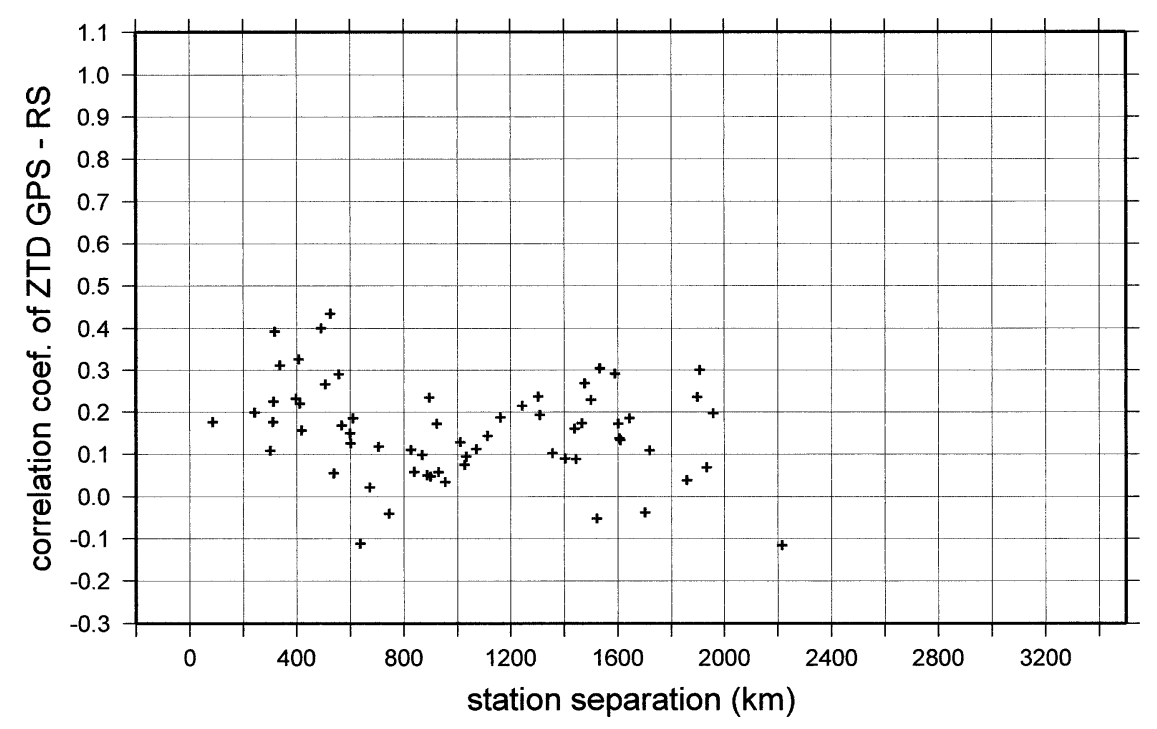

FIG. 13. Correlation coefficient for ZTD GPS-radiosonde differences compared between sites as a function of separation between the GPS sites.

The standard deviation is relatively well understood and shows similar trends in both the radiosonde and HIRLAM comparisons. It is well below the signal level; therefore, we do not expect it to pose any particular problems.

We also showed that significant biases exist in the radiosonde data that are most likely due to day/night biases and that reach up to $15 \mathrm{~mm}$ ZTD during humid summer months. Temperature biases have been shown to exist in radiosonde comparisons where multiple types of radiosonde equipment have been flown simultaneously with a reference radiosonde (WMO 1996). There is a background positive bias of less than $5 \mathrm{~mm}$ of ZTD that is present in both day and night radiosonde data comparisons that does not correlate with seasonal variations in humidity. This is the maximum likely bias that may be attributed to the GPS data or data-processing method.

The biases show a coherent regional pattern over timescales on the order of 1 month, indicating that they are more or less typical for a given geographical location. In addition, however, there is some seasonal variation in the amplitude of these biases. One possible approach is to remove a monthly or weekly mean bias from the GPS ZTD data before assimilation into an NWP model. However, it is not the best approach for considering future applications for climate studies, where the long-term seasonal biases may interfere with the inter-

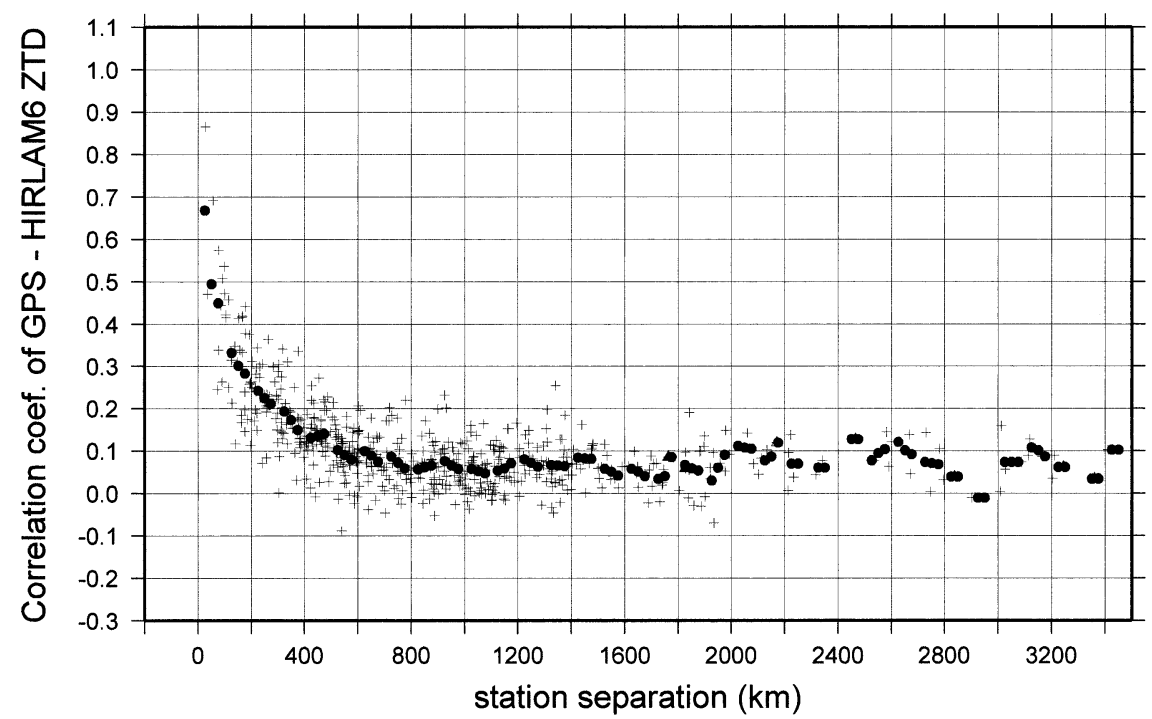

FIG. 14. The correlation coefficient for the GPS-HIRLAM6 differences compared between sites as a function of separation. The circles are the correlation coefficients averaged over $50-\mathrm{km}$ bins. 
pretation of long-term trends in the GPS ZTD data. Interestingly, long-term biases are small or nonexistent in the comprehensive studies that have been carried out by NOAA in the midwestern United States. The most obvious difference would be the scale of the topography and resulting complications in synoptic weather patterns, such as secondary cyclogenesis in the Alps and Mediterranean, as compared with the relatively flat and homogeneous land surface of the midwestern United States.

The GPS-radiosonde biases are not unambiguously correlated with the GPS-HIRLAM biases, making it likely that there are several remaining sources of bias in the datasets. We now provide a short discussion of these potential error sources.

\section{a. "Instrumental" GPS error sources}

The mapping function describes the elevation angle dependence of the geometrical ray path and assumes a horizontally stratified atmosphere with no azimuthal variations in the volume sampled by the receiver. We use the Niell mapping functions, which provide empirical relations for that mapping based on atmospheric datasets with typical scale heights. If the average vertical structure at the site is significantly different from that on which the functions were based, or varies seasonally, then this could create biases. The Niell mapping functions have been shown to be the best average functions for reducing these biases (Fang et al. 1998; Niell 2000) and in fact, this is true for our dataset as well, averaged across the entire network. The regional and seasonal variations in the biases could be due to systematic local variations, and should be the subject of further study. Some stations may be placed where the axisymmetric assumption is not true over hours, days, weeks, or even over the year. A site at the coast, on average, may have a marked difference in atmospheric properties to the inland and seaside, at least during periods of days and/ or over the diurnal cycle during certain weather conditions. Likewise, a site that has mountains to the one side and lowlands to the other may not be symmetric because of differences in the boundary layer or problems with the ability of the receiver to monitor down to the same elevation angle in all directions. Even for axisymmetric structures, upper-level moisture that creates a significant departure from an exponentially distributed humidity profile would tend to produce a high bias from the mapping function approximations. It would most likely create a positive bias, because the ray pathlength variation would tend to be positive. The magnitude of any bias, based on the differences that could be observed using a range of nonoptimal mapping functions in past studies (Fang et al. 1998), would probably be on the order of 5-10 $\mathrm{mm}$ of ZTD.

Local multipath of the GPS signal can cause systematic variations in the data at low elevations that could possibly cause a bias in the ZTD. Normally, the geodetic sites that are used here have good sky visibility and multipath-reducing choke-ring antennas in order to reduce this effect. Recently, in the Japan GPS Earth Observation Network (GEONET), it was found that the metallic structure of the geodetic monument changed the antenna phase-center and multipath variations significantly, leading to biases as large as $7 \mathrm{~mm}$ of ZTD (Ohtani 2002). The possibility that this could be a problem at the Mediterranean sites is less likely, because the monuments are typically concrete pillars. This could be tested, however, by running a nearby standard antenna on a tripod at a site with a high bias. Multipath-induced errors would not be a likely cause of biases that had seasonal variations. Foliage on trees blocking visibility to the site could produce a seasonal variation in multipath; however, the MAGIC network sites have no such obstructions.

Persistent large-scale horizontal gradients in atmospheric structure could lead to regional biases. Solving for ZTD gradient parameters in orbit calculations has been shown to decrease the rmse of the orbits. Thus, there is some trade-off that should be the subject of future investigation, through examination of systematic variations in vertical coordinates and orbital geometry. Whether this type of bias could attain levels comparable to the biases that are seen $(5-10 \mathrm{~mm}$ of ZTD) is not known.

Atmospheric and hydrologic loading are phenomena where the earth's atmosphere or the distribution of continental water exerts loads on the surface and depresses the crust. The vertical motion due to this deformation is large enough to be detected in the signal by the GPS. This would create a signal that is correlated with the dry delay term of the tropospheric delay, but would tend to average out for periods greater than the tidal cycle. High pressure systems would create a positive bias in the GPS signal, though not as large as the 15-mm ZTD biases that we have observed. The feasibility of firstorder modeling of the signal and separating it from the zenith delay signal requires further investigation.

\section{b. Radiosonde errors}

Radiosondes have typical instrumental temperature sensor standard errors between 0.2 and $0.5 \mathrm{~K}$, and relative humidity standard errors are $5 \%$. In multiple flight comparisons, the two-standard-deviation nighttime flight-to-flight variation of temperature is within this standard error. However the flight-to-flight temperature variation during the day is 2-3 times as high. There are biases between types of radiosondes that have been documented as a result of comparison tests (WMO 1996). These show that variations in solar radiation heating of the instruments remain a significant cause of systematic errors in measured temperature and humidity. This shows up most in differences between day and night radiosonde launches where temperatures can be biased by $0.9,1.3$, and $2.2 \mathrm{~K}$ at 300,100 , and $30 \mathrm{hPa}$, re- 
spectively, for the type of sonde most frequently used in western Europe. Software corrections are applied for solar radiation heating but are based on average flight conditions. Radiosondes that fly over the relatively low albedo ocean where backscattered radiation is lower may have corrections applied that may be too large by at least $20 \%$. Backscattering from thick upper clouds with high albedo may result in a software correction that is too small.

Most radiosondes are corrected for the thermal lag of the sensors, which can be given by a time constant multiplied by the velocity of ascent and the temperature gradient. The error is from 0.1 to $0.3 \mathrm{~K}$. However, in strong temperature inversions the errors may be very much larger.

Biases between types of relative humidity sensors show systematic differences after passing through low clouds or fog, where the external temperature sensors have clearly become wet. This increases relative humidity by at least $10 \%$ on average (Nash et al. 1995). The dewpoint pressure that is reported is calculated from the relative humidity measurement multiplied by the saturated vapor pressure derived from the radiosonde temperature. An error of $-1.5 \%$ at $50 \%$ humidity can result because the thermal lag of the relative humidity sensor is usually much longer than the thermal lag of the temperature sensor. This error can decrease the relative humidity by $4 \%-5 \%$ at temperatures from $-10^{\circ}$ to $-30^{\circ} \mathrm{C}$. The actual correction for this error was not determined in the radiosonde comparison because the error seemed to affect all types of radiosondes in a similar manner. The flight-to-flight sonde error (two standard deviations) for typical European radiosondes is $6 \%$ from $40 \%-90 \%$ relative humidity and $4 \%$ from $10 \%-$ $20 \%$ relative humidity.

Last, significant humidity errors have been found to depend on the age of the radiosonde, because of the gradual absorption of materials in which the radiosondes are stored that impede the influx of water molecules to the sensor (Liljegren et al. 1999). This has been shown to lead to an increase in the bias between the microwave radiometer and radiosonde data of $1.55 \mathrm{~kg} \mathrm{~m}^{-2}$ of integrated water vapor during the summer humid season or about an increase of $10 \mathrm{~mm}$ ZTD, and an increase in the standard deviation during the summer months as well. This can now be corrected if the model number of the radiosonde is known. For our study, we did not have direct access to this information. While this error has properties similar to the observations made about our data, it does not explain the low bias for nighttime launches.

In general, modern radiosondes typically used in western Europe provide high-accuracy measurements, and a good deal of progress has been accomplished through the intercomparison tests to derive correction algorithms. However, we see that there are some types of situations that may still cause systematic errors: these are the day-night differences, differences due to solar radiation because of significantly different albedo, systematic errors due to thermal lag in ascent through inversion layers, systematic humidity errors due to flight through fog, and systematic errors due to the age of the radiosonde. These represent potential systematic sources of bias that in some cases could correlate with local site conditions, such as coastal sites that sample cases preferentially over the ocean or land, depending on the sea breeze. Further pursuing such possible correlations is a subject of future study.

\section{Conclusions}

The MAGIC project GPS ZTD data, because of its long-term continuous comparison with radiosondes and NWP model fields, is a unique dataset for evaluating the error statistics of GPS ZTD data over several complete annual cycles. The dataset is also unique in that the HIRLAM forecast output is available at 15-min intervals for the entire period, not the typical 6-h forecast interval, so that comparisons can be carried out at a large range of timescales. The dataset contains 51 sites and covers $2.5 \mathrm{yr}$. The dataset also covers an altitude range from sea level to $2500 \mathrm{~m}$, with the climatic conditions varying from the warm, humid climatic conditions of the Mediterranean to Alpine conditions.

The GPS ZTD data show annual variations with amplitudes from 30 to $70 \mathrm{~mm}$ and shorter-timescale variability with an rms of up to $40 \mathrm{~mm}$. The variation of GPS ZTD on the annual timescale is positively correlated with temperature and the temperature-induced humidity variations. The annual mean GPS ZTD is dependent on the pressure and, hence, altitude of the site.

Comparing 14 sites with radiosonde data within a distance of $50 \mathrm{~km}$ shows that the two datasets are in very close agreement, with biases less than $7 \mathrm{~mm}$ of ZTD for 9 out of 14 sites, and standard deviations of $12 \mathrm{~mm}$. The high-bias sites tend to be high-humidity, low-altitude coastal sites. The biases increase during the summer months, but only for the daytime launches, illustrating that at least part of these biases are most likely associated with day/night radiosonde biases and are not an artifact of the GPS data processing. The scatter of the residuals increases during the summer months when more humidity is present and the humidity fields have more temporal variability.

In the comparison with ZTD estimates calculated from HIRLAM, the GPS-HIRLAM biases are smaller than for the radiosondes, only $3.4 \mathrm{~mm}$ of ZTD. The standard deviation of the GPS-HIRLAM residuals is greater than for radiosondes, more than $18 \mathrm{~mm}$ of ZTD. This indicates there is significant additional information contained in the GPS data that has the potential to improve HIRLAM initial humidity fields. The strong seasonal dependence of the errors must be considered in the statistics used for assimilation.

Examination of temporal structure functions and analysis of the annual variability in the GPS ZTD data in- 
dicated that GPS ZTD data are sensitive enough to reliably show spatial variations in average upper-air integrated water vapor over yearly timescales. Comparisons with midnight radiosonde launches show that these data are as reliable as radiosondes and with only a small but stable bias. These are promising conclusions for the potential use of GPS ZTD data for studying climatic variations of integrated water vapor and validation of regional climate models. However, the biases, which have some seasonal variation and some coherent regional variation on monthly timescales, must be further investigated before their use in climate studies.

Acknowledgments. This work was carried out as part of the MAGIC project (see information online at http:// www.acri.fr/magic), funded in part by the European Commission DGXII Environment and Climate Program (EC Contract ENV4-CT98-0745). We thank the many institutions and academic organizations that provide GPS observation data freely to the research community, and we thank, in particular, the Royal Observatory of the Armada in San Fernando, the Institute of Cartography in Catalonia, and the Italian Space Agency. We acknowledge the contribution of the International GPS Service (IGS) and the IGS analysis centers through their provision of quality orbits and GPS archives. Figures were prepared using the GMT software. We also thank the anonymous reviewers for their constructive comments.

\section{REFERENCES}

Askne, J., and H. Nordius, 1987: Estimation of tropospheric delay for microwaves from surface weather data. Radio Sci., 22, 379386.

Bar-Sever, Y. E., P. M. Kroger, and J. A. Borjesson, 1998: Estimating horizontal gradients of tropospheric path delay with a single GPS receiver. J. Geophys. Res., 103, 5019-5035.

Bevis, M., S. Businger, T. A. Herring, C. Rocken, A. Anthes, and R. Ware, 1992: GPS meteorology: Remote sensing of atmospheric water vapor using the global positioning system. J. Geophys. Res., 97, 15 787-15 801.

,-- , S. Chiswell, T. A. Herring, R. A. Anthes, C. Rocken, and R. H. Ware, 1994: GPS meteorology: Mapping zenith wet delays onto precipitable water. J. Appl. Meteor., 33, 379-386.

Bock, Y., R. I. Abbot, C. C. Counselman, S. A. Gourevitch, and R. W. King, 1986: Interferometric analysis of GPS phase observations. Manuscr. Geod., 11, 282-288.

Davis, J. L., T. A. Herring, I. I. Shapiro, A. E. Rogers, and G. Elgered, 1985: Geodesy by radio interferometry: Effects of atmospheric modeling errors on estimates of baseline length. Radio Sci., 20, $1593-1607$.

Doswell, C. A., C. Ramis, R. Romero, and S. Alonso, 1998: A diagnostic study of three heavy precipitation episodes in the western Mediterranean region. Wea. Forecasting, 13, 102-124.

Duan, J., and Coauthors, 1996: GPS meteorology: Direct estimation of the absolute value of precipitable water vapor. J. Appl. Meteor., 35, 830-838.

Elgered, G., J. L. Davis, T. A. Herring, and I. I. Shapiro, 1991: Geodesy by radio interferometry-Water vapor radiometry for estimation of the wet delay. J. Geophys. Res., 96, 6541-6555.

, J. M. Johansson, B. O. Ronnang, and J. L. Davis, 1997: Mea- suring regional atmospheric water vapor using the Swedish permanent GPS network. Geophys. Res. Lett., 24, 2663-2666.

Elliott, W. P., 1993: Effects of conversion algorithms on reported upper-air dewpoint depressions. Bull. Amer. Meteor. Soc., 74, $1323-1325$.

- and D. J. Gaffen, 1991: On the utility of radiosonde humidity archives for climate studies. Bull. Amer. Meteor. Soc., 72, 15071520.

Emardson, T. R., and H. J. P. Derks, 2000: On the relation between the wet delay and the integrated precipitable water vapour in the European atmosphere. Meteor. Appl., 7, 61-68.

_, G. Elgered, and J. M. Johansson, 1998: Three months of continuous monitoring of atmospheric water vapor with a network of global positioning system receivers. J. Geophys. Res., 103, 1807-1820.

_- J. Johansson, and G. Elgered, 2000: The systematic behavior of water vapor estimates using four years of GPS observations. IEEE Trans. Geosci. Remote Sens., 38, 324-329.

Eskridge, R. E., O. A. Alduchov, I. V. Chernykh, Z. Panmao, A. C. Polansky, and S. R. Doty, 1995: A Comprehensive Aeorological Reference Data Set (CARDS): Rough and systematic errors. Bull. Amer. Meteor. Soc., 76, 1759-1775.

Fang, P., M. Bevis, Y. Bock, S. Gutman, and D. Wolfe, 1998: GPS meteorology: Reducing systematic errors in geodetic estimates for zenith delay. Geophys. Res. Lett., 25, 3583-3586.

Flores, A., A. Escudero, M. J. Sedo, and A. Rius, 2000: A near real time system for tropospheric monitoring using IGS hourly data. Earth Planets Space, 52, 681-684.

Ge, M., E. Calais, and J. Haase, 2000: Reducing satellite orbit error effects in near real-time GPS zenith tropospheric delay estimation for meteorology. Geophys. Res. Lett., 27, 1915-1919.

Gutman, S. I., and S. G. Benjamin, 2001: The role of ground-based GPS meteorological observations in numerical weather prediction. GPS Solution, 4, 16-24.

Haase, J., and Coauthors, 2001: The contributions of the MAGIC project to the COST 716 objectives of assessing the operational potential of ground-based GPS meteorology on an international scale. Phys. Chem. Earth Solid Earth Geod., 26, 433-437.

Herring, T. A., 1990: Geodesy by radiointerferometry: The application of Kalman filtering to the analysis of VLBI data. J. Geophys. Res., 95, 12 561-12 581.

Iwabuchi, T., I. Naito, and N. Mannoji, 2000: A comparison of global positioning system retrieved precipitable water vapor with the numerical weather prediction analysis data over the Japanese Islands. J. Geophys. Res., 105, 4573-4585.

Jarlemark, P. O. J., and G. Elgered, 1998: Characterizations of temporal variations in atmospheric water vapor. IEEE Trans. Geosci. Remote Sens., 36, 319-321.

King, R. W., and Y. Bock, 1999: Documentation for the GAMIT GPS analysis software. Release 10.0, Massachusetts Institute of Technology, 206 pp.

Kouba, J., and Y. Mireault, 1998: 1997 Analysis coordinator report. Jet Propulsion Laboratory 1997 IGS Annual Rep. JPL 400-786 10/98, 23-69.

Kuo, Y.-H., X. Zou, and Y.-R. Guo, 1996: Variational assimilation of precipitable water using a nonhydrostatic mesoscale adjoint model. Part I: Moisture retrieval and sensitivity experiments. Mon. Wea. Rev., 124, 122-147.

Lemoine, F. G., and Coauthors, 1997: The development of the NASA GSFC and NIMA Joint Geopotential Model. Gravity, Geoid and Marine Geodesy, H. F. J. Segawa and S. Okubo, Eds., International Association of Geodesy Symposia, 461-469.

Lide, D. R., 1992: Handbook of Chemistry and Physics. 73d ed. Chemical Rubber Publishing Company, 2407 pp.

Liljegren, J., B. Lesht, T. VanHove, and C. Rocken, 1999: A comparison of integrated water vapor from microwave radiometer, balloon-borne sounding system and global positioning system. Proc. Ninth Atmospheric Radiation Measurement Program Science Team Meeting, San Antonio, TX, Department of Energy, $1-8$. 
Mader, G. L., cited1999: GPS antenna calibration at the National Geodetic Survey. [Available online at http://www.grdl.noaa.gov/ GRD/GPS/Projects/ANTCAL/Files/summary.html.]

Majewski, D., 1985: Balanced initial and boundary values for a limited area model. Beitr. Phys. Atmos., 58, 147-159.

Mendes, V. d. B., 1999: Modeling the neutral-atmosphere propagation delay in radiometric space techniques. Ph.D. thesis, University of New Brunswick, 349 pp.

Nash, J., J. B. Elms, and T. J. Oakley, 1995: Relative humidity sensor performance observed in recent international radiosonde comparisons. Preprints, Ninth Symp. on Meteorological Observations and Instrumentation, Charlotte, NC, Amer. Meteor. Soc., 43-48.

Niell, A. E., 2000: Improved atmospheric mapping functions for VLBI and GPS. Earth Planets Space, 52, 699-702.

Ohtani, R., 2002: Results of GPS meteorology project of Japan. Extended Abstracts, COST Action 716 Workshop "Exploitation of Ground-based GPS for Meteorology,” Potsdam, Germany, European Commission, 9 .

Pacione, R., C. Sciarretta, F. Vespe, C. Faccani, R. Ferretti, E. Fionda, C. Ferraro, and A. Nardi, 2001: GPS meteorology: Validation and comparisons with ground-based microwave radiometer and mesoscale model for the Italian GPS permanent stations. Phys. Chem. Earth, 26A, 139-145.

Parker, D. E., and D. I. Cox, 1995: Towards a consistent global climatological rawinsonde data-base. Int. J. Climatol., 14, 473 496.

Rocken, C., R. Ware, T. Van Hove, F. Solheim, C. Alber, and J. Johnson, 1993: Sensing atmospheric water vapor with the global positioning system. Geophys. Res. Lett., 20, 2631-2634.

- T. V. Hove, J. Johnson, F. Solheim, R. Ware, M. Bevis, S. Chiswell, and S. Businger, 1995: GPS/STORM-GPS sensing of atmospheric water vapor for meteorology. J. Atmos. Oceanic Technol., 12, 468-478.

Ruffini, G., L. P. Kruse, A. Rius, B. Burki, and L. Cucurull, 1999: Estimation of tropospheric zenith delay and gradients over the Madrid area using GPS and WVR data. Geophys. Res. Lett., 26, 447-450.

Saastamoinen, J., 1972: Atmospheric correction for the troposphere and stratosphere in radio ranging of satellites. The Use of Artificial Satellites for Geodesy, S. W. Henriksen et al., Eds., Amer. Geophys. Union, 247-251.

Sass, B. H., N. W. Nielsen, J. U. Jorgensen, and B. Ammstrup, 1999: The operational HIRLAM system at DMI. DMI Tech. Rep., 99$21,43 \mathrm{pp}$

Smith, E. K., and S. Weintraub, 1953: The constants in the equation for atmospheric refractive index at radio frequencies. Proc. IRE, 41, 1035-1037.

Smith, T. L., S. G. Benjamin, B. Schwartz, and S. I. Gutman, 2000: Using GPS-IPW in a 4-D data assimilation system. Earth Planets Space, 52, 921-926.

Thayer, G. D., 1974: An improved equation for the radio refractive index of air. Radio Sci., 9, 803-807.

Tralli, D. M., and S. M. Lichten, 1990: Stochastic estimation of tropospheric path delays in global positioning system geodetic measurements. Bull. Geod., 64, 127-159.

Tregoning, P., R. Boers, D. O'Brien, and M. Hendy, 1998: Accuracy of absolute precipitable water vapor estimates from GPS observations. J. Geophys. Res., 103, 28 701-28 710.

Treuhaft, R. N., and G. E. Lanyi, 1987: The effect of the dynamic wet troposphere on radio interferometric measurements. Radio Sci., 22, 251-265.

Vedel, H., 2000: MAGIC project radiosonde data specification document. MAGIC Project Rep. D05210, 4 pp.

- 2001: Calculation of delays from meteorological data, comparison of NWP model and observed delays. Phys. Chem. Earth, 26A, 497-502.

Wade, C. G., 1994: An evaluation of problems affecting the measurement of low relative humidity on the United States radiosonde. J. Atmos. Oceanic Technol., 11, 687-700.

Webb, F. H., and J. F. Zumberge, 1997: An introduction to GIPSY/ OASIS II. JPL Publ. D-11088, Jet Propulsion Laboratory, Pasadena, CA, $177 \mathrm{pp}$

WMO, 1996: Guide to Meteorological Instruments and Methods of Observation. 6th ed. World Meteorological Organization, 420 pp.

Yang, S., B. H. Sass, G. Elgered, J. M. Johansson, and T. R. Emardson, 1999: A comparison of the precipitable water vapor estimates by an NWP simulation and GPS observations. J. Appl. Meteor., 38, 941-956.

Yuan, L. L., R. A. Anthes, R. H. Ware, C. Rocken, W. D. Bonner, M. G. Bevis, and S. Businger, 1993: Sensing climate change using the global positioning system. J. Geophys. Res., 98, $14925-14937$.

Zou, X., and Y.-H. Kuo, 1996: Rainfall assimilation through an optimal control of initial and boundary conditions in a limited-area mesoscale model. Mon. Wea. Rev., 124, 2859-2882.

Zumberge, J. F., M. B. Heflin, D. C. Jefferson, M. M. Watkins, and F. H. Webb, 1997: Precise point positioning for the efficient and robust analysis of GPS data from large networks. J. Geophys. Res., 102, 5005-5017. 